Paula Kiyomi Onaga Yokota

\title{
AVALIAÇÃO MICROBIOLÓGICA E IMPORTÂNCIA DA ADEQUAÇÃO ANTIMICROBIANA PARA OS PACIENTES COM SEPSE GRAVE E CHOQUE SÉPTICO
}

Dissertação apresentada à Sociedade
Beneficente Israelita Brasileira Albert
Einstein, para obtenção do Título de Mestre
em Ciências da Saúde.

São Paulo 
Paula Kiyomi Onaga Yokota

\title{
AVALIAÇÃO MICROBIOLÓGICA E IMPORTÂNCIA DA ADEQUAÇÃO ANTIMICROBIANA PARA OS PACIENTES COM SEPSE GRAVE E CHOQUE SÉPTICO
}

\author{
Dissertação apresentada a Sociedade \\ Beneficente Israelita Brasileira Albert \\ Einstein, para obtenção do Título de Mestre \\ em Ciências da Saúde.
}

Orientador: Dr. Alexandre Rodrigues Marra 
Y54a

Yokota, Paula Kiyomi Onaga

Avaliação microbiológica e importância da adequação antimicrobiana para os pacientes com sepse grave e choque séptico / Paula Kiyomi Onaga Yokota. -- 2015.

$\mathrm{x}, 36 \mathrm{f}$.

Dissertação (Mestrado) - Sociedade Beneficente Israelita Brasileira Albert Einstein. Instituto Israelita de Ensino e Pesquisa Albert Einstein. Programa de Pós-Graduação em Ciências da Saúde.

Título em inglês: Microbiology evaluation and importance of antimicrobial adequacy for patients with severe sepsis and septic shock.

1. Microbiologia. 2. Antimicrobianos. 3. Sepse. 4. Choque séptico. 5. Mortalidade. I. Marra, Alexandre Rodrigues. II. Título.

NLM - WC 240

Elaborada pelo Sistema Einstein Integrado de Bibliotecas 
SOCIEDADE BENEFICENTE ISRAELITA BRASILEIRA ALBERT EINSTEIN

Coordenador do Curso de Pós-Graduação Prof. Dr. Luiz Vicente Rizzo 


\title{
Paula Kiyomi Onaga Yokota
}

\section{AVALIAÇÃO MICROBIOLÓGICA E IMPORTÂNCIA DA ADEQUAÇÃO ANTIMICROBIANA PARA OS PACIENTES COM SEPSE GRAVE E CHOQUE SÉPTICO}

Presidente da banca: Dr. Alexandre Rodrigues Marra

\author{
BANCA EXAMINADORA
}
Membros titulares:
Dr. Carlos Albert Pires
Dr. David Salomao Lewi

Membros suplentes:

Dra. Alline Artigiani Lima Tribst

Dr. Gustavo Faissol Janot de Matos

Aprovada em: 19/11/2015. 


\section{Dedicatória}

Aos meus pais, Paulo e Sônia, por todo sacrifício para me verem feliz, pelo contínuo incentivo e apoio dado durante toda a minha vida.

Ao meu irmão, Anderson, pelos incontáveis momentos de help desk $24 \mathrm{~h}$, além de contribuir significativamente na minha vida profissional.

Às minhas tias, Rosa e Alice, pelo constante acolhimento desde 0 início da faculdade, por todo o suporte em todos os momentos, tornando a jornada em São Paulo menos penosa.

Ao meu namorado, André, pelo grande carinho, paciência e compreensão de sempre. 


\section{Agradecimentos}

Minha eterna gratidão a Deus, por prover mais do que mereço e muito mais do que imagino.

Ao Diretor da Prática Médica Prof. Dr. Oscar Fernando Pavão dos Santos, sou muito grata pela oportunidade em conhecer o Dr. Alexandre Marra, além de todo incentivo e preocupação, que foram significativos para meu desenvolvimento profissional.

Ao Dr. Alexandre Rodrigues Marra, sou muitíssimo grata e sinto grande privilégio em ter sido aceita como sua orientanda. Muito obrigada pelo aceite, pelas oportunidades em conhecer a prática da pesquisa clínica, pela constante prontidão em orientar $e$ incentivar, pela preocupação $e$ interesse no meu desenvolvimento profissional. Espero ter a oportunidade de retribuir.

Ao Coordenador da Epidemiologia, Paulo David Scatena Gonçales, pela oportunidade em trabalhar na área, sua confiança em meu profissionalismo permitiu grande liberdade em poder conciliar as disciplinas e minha rotina de trabalho. Além da amizade, paciência, e compartilhar seus conhecimentos em Excel.

À Gerente Médica do Programa de Cardiologia, Dra. Márcia Makdisse, desde o início da graduação, me proporcionou inesquecíveis e significativos momentos de aprendizagem pessoal e profissional. Além de sua preocupação e interesse no meu crescimento como Enfermeira, a nova oportunidade de carreira dentro do Programa, e pelo incentivo em continuar e terminar o meu mestrado.

Ao Coordenador de Qualidade do Programa de Cardiologia e do Núcleo de Apoio à Pesquisa Cardiovascular, Dr. Marcelo Katz, pela confiança em meu trabalho, às horas cedidas para finalizar o mestrado, pela preocupação constante.

À Coordenadora Médica do setor de microbiologia do Hospital Israelita Albert Einstein, Dra. Marinês Dalla Valle Martino, pelas horas cedidas para me ajudar à coleta dos dados relacionados ao perfil microbiológico, e cuja dedicação e paciência foram inestimáveis.

À estatística do Instituto Israelita de Ensino e Pesquisa, Elivane da Silva Victor, por compartilhar seu conhecimento nessa área admirável que é a estatística, por sua compreensão, e empenho para ajudar com os testes estatísticos.

Ao Dr. Marcelino de Souza Durão e ao Dr. Michael B. Edmond pelas horas dedicadas para a contribuição na publicação. 
A todos os demais docentes e assistentes do Programa de PósGraduação Stricto Sensu do Instituto de Ensino e Pesquisa do Hospital Albert Einstein, que contribuíram com seus inestimáveis ensinamentos para minha formação e constantes incentivos.

À Laudiceia Almeida e Jannaina Pinho de Oliveira por todo esforço, dedicação, solidariedade e paciência, ajudando na solicitação de informações e agilizando os processos para a concretização deste trabalho.

A todos os amigos do Programa de Pós-Graduação Stricto Sensu do Instituto de Ensino e Pesquisa do Hospital Albert Einstein, velhos e novos, sempre serei grata pela oportunidade em aprender com vocês e a colaboração de todos nas atividades em grupo. 


\section{Sumário}

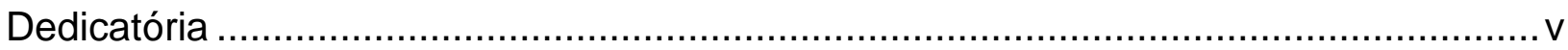

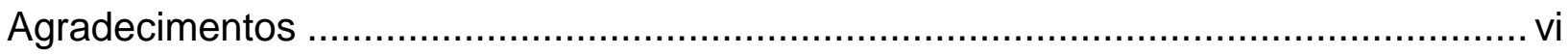

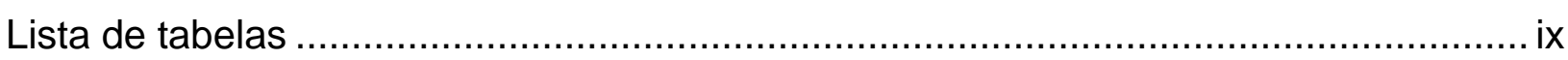

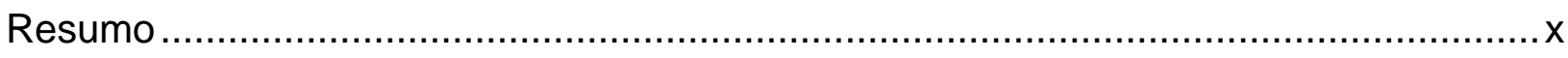

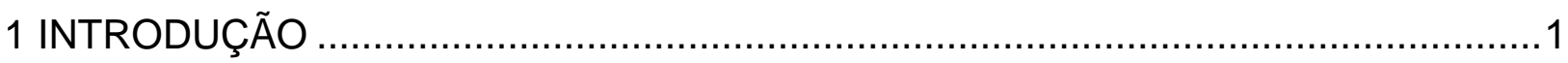

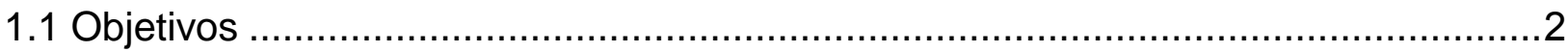

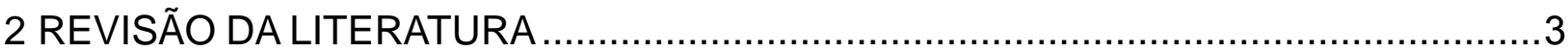

2.1 Sepse: definições, protocolos, indicadores de qualidade .................................. 5

2.2 Adequação da terapia antimicrobiana ......................................................

2.3 Perfil microbiológico e mecanismos de resistência ........................................8

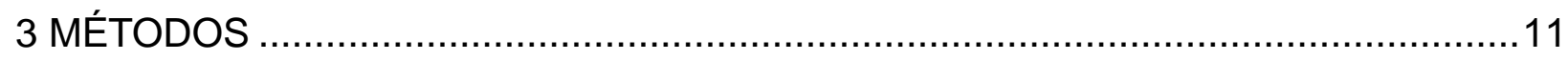

3.1 Terapêutica antimicrobiana ................................................................. 12

3.2 Métodos microbiológicos ............................................................................ 13

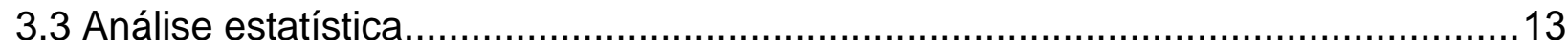

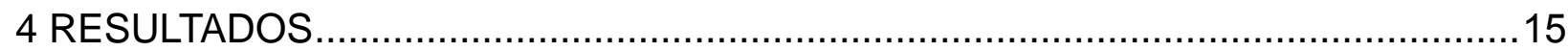

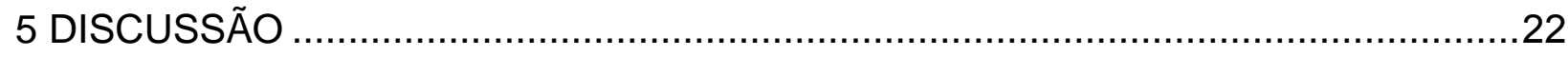

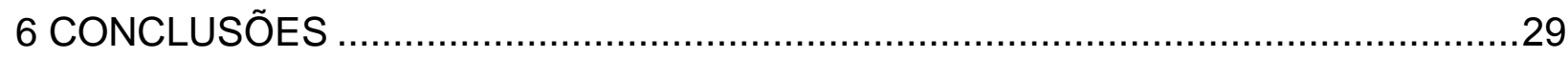

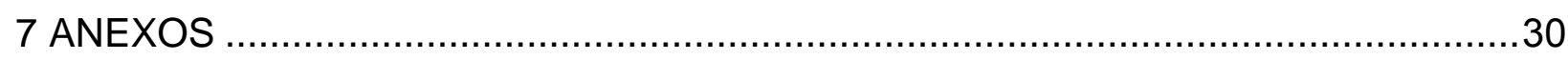

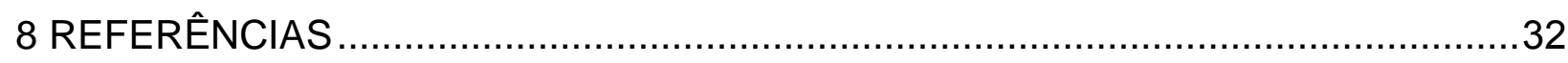

Abstract 


\section{Lista de tabelas}

Tabela 1. Características demográficas e clínicas dos pacientes com sepse grave e choque séptico 15

Tabela 2. Análise da comparação dos itens do pacote sepse entre os anos de 2010, 2011 e 2012 16

Tabela 3. Análise dos fatores de risco para mortalidade hospitalar para os pacientes com sepse grave ou choque séptico 17

Tabela 4. Análise dos fatores de risco para mortalidade hospitalar para pacientes com sepse grave ou choque séptico que apresentaram infecção da corrente sanguínea....18 Tabela 5. Descrição dos fatores de risco em relação à inadequação antimicrobiana dos pacientes com sepse grave ou choque séptico que tiveram infecção da corrente sanguínea 19

Tabela 6. Análise dos fatores de risco para a inadequação antimicrobiana dos pacientes com sepse grave ou choque séptico que tiveram infecção da corrente sanguínea. 19

Tabela 7. Perfil microbiológico identificados nas hemoculturas com crescimento de microrganismos dos pacientes com sepse grave ou choque séptico

Tabela 8. Classificação dos microrganismos identificados nas hemoculturas em que houve crescimento 21 


\section{Resumo}

Objetivo: Determinar o perfil microbiológico e a adequação antimicrobiana dos pacientes que desenvolveram sepse grave e choque séptico internados na unidade de terapia intensiva adulto em um hospital privado de São Paulo. Métodos: Este estudo foi realizado na unidade de terapia intensiva adulto, de um hospital privado terciário de São Paulo, Brasil. Foi um estudo de coorte retrospectivo realizado entre julho de 2005 a dezembro de 2012, em pacientes com sepse grave e choque séptico. Resultados: Um total de 1.279 pacientes foram identificados como sepse grave e choque séptico, dos quais $358(32,1 \%)$ apresentaram infecção da corrente sanguínea. A taxa de mortalidade hospitalar foi de $29 \%$. Na avaliação do pacote sepse, ao longo do tempo houve um aumento progressivo de adesão ao protocolo, com diferenças estatisticamente significativas nos últimos anos do estudo. Observou-se também uma diminuição significativa na mortalidade. Em pacientes com infecção de corrente sanguínea, após ajuste para outras variáveis, a administração da terapêutica antimicrobiana adequada foi associado a uma diminuição da mortalidade em pacientes com sepse grave e choque séptico $(p=0,023)$. Conclusões: $A$ administração de terapêutica antimicrobiana adequada foi independentemente associada com um declínio da mortalidade em pacientes com sepse grave e choque séptico. Com o protocolo, a adesão aumentou ao longo do tempo, a mortalidade hospitalar diminuiu, o que reforça a necessidade de se implementar as diretrizes institucionais e de fiscalizar o cumprimento da terapia antimicrobiana adequada. 


\section{INTRODUÇÃO}

Sepse grave e choque séptico são manifestações preocupantes de uma infecção sistêmica e as principais causas de internação em unidades de terapia intensiva, onde se estima que 19 milhões de casos ocorram no mundo a cada ano, resultando na morte de um em cada quatro desses pacientes. ${ }^{(1,2)}$ De acordo com o Ministério da Saúde do Brasil, através do banco de dados relacionado à saúde, essas manifestações são responsáveis por uma média de $41 \%$ do total anual de mortalidade intra-hospitalar em adultos, no período de 2008 até agosto de 2013. ${ }^{(3)}$

Apenas na região sudeste, a taxa de mortalidade é de $46 \%,{ }^{(3)}$ o que reforçou a justificativa do Hospital Israelita Albert Einstein em participar da Campanha Sobrevivendo à Sepse (Surviving Sepsis Campaign) a partir de 2004, bem como do projeto mundial "Stop Sepsis, Save Lives". ${ }^{4,5)}$

De acordo com as diretrizes internacionais, para o tratamento imediato de sepse grave ou do choque séptico, a administração de antibióticos deve ocorrer dentro da primeira hora do reconhecimento, pois impacta diretamente na mortalidade. ${ }^{(2)}$

Desde 2006, o Hospital Israelita Albert Einstein utiliza em sua rotina dos pacientes graves o pacote sepse. ${ }^{(6)}$ As recomendações de tratamento, de acordo com as diretrizes, foram organizadas em dois pacotes: um pacote de reanimação (que contempla seis procedimentos para início imediato e obrigatoriamente cumpridos dentro de seis horas após o reconhecimento dos primeiros sintomas) e um pacote de gerenciamento (com quatro procedimentos para serem concluídos no prazo de 24 horas). ${ }^{(4)}$

No entanto, não há nenhuma avaliação da adequação da terapia antimicrobia na após a coleta de hemoculturas em estudos do pacote de sepse, que é uma das principais medidas para reduzir a mortalidade em pacientes criticamente doentes por processos infecciosos. E com o passar do tempo em não se adequar a terapêutica antimicrobiana, existe um risco aumentado de morte. ${ }^{(7-9)}$ 


\subsection{Objetivos}

1. Determinar o perfil microbiológico dos pacientes que desenvolveram sepse grave e choque séptico internados na unidade de terapia intensiva adulto no Hospital Israelita Albert Einstein.

2. Determinar a adequação antimicrobiana dos pacientes com sepse grave e choque séptico internados na unidade de terapia intensiva adulto no Hospital Israelita Albert Einstein. 


\section{REVISÃO DA LITERATURA}

O termo sepse foi citado pela primeira vez por volta de 700 antes de Cristo, nos poemas de Homero, ${ }^{(10)}$ portanto, de origem grega, "sêpsis" que significa putrefação e carne podre. ${ }^{(11)}$ Logo foi encontrado nas descrições de Hipócrates, que associava a algo perigoso e com comprometimento biológico odorífero, que poderia ocorrer no organismo de qualquer pessoa, principalmente jovens saudáveis. Ao longo da história da humanidade, o impacto como manifestação de diferentes endemias e epidemias, em sua forma septicêmica, dizimou um terço da população europeia no século XIV. ${ }^{(10)}$

Apesar do avanço da medicina, como também da ciência de modo geral, descobertas como a identificação de microrganismos e dos próprios antibióticos, poderiam ter erradicado a sepse. ${ }^{(11)}$ Entretanto, no mundo todo, milhões de pessoas são afetadas anualmente, com o agravante de altas taxas de mortalidade, que não se restringem apenas às regiões menos favorecidas. ${ }^{(11-13)}$ Porém, o fato de se reconhecer os primeiros sinais e sintomas da doença feita de modo tardio, concomitante à demora em encaminhar o paciente a um serviço com atendimento intensivo, ainda são problemas atuais, que acomete vários lugares. ${ }^{(10)}$

Países com políticas públicas melhor organizadas, como Estados Unidos, Austrália, Canadá; que dispõem de boa infraestrutura tanto de atendimento de saúde para a população, como de pesquisa, a mortalidade decorrente da sepse diminuiu. Entretanto, no Brasil, ainda não é a mesma realidade; ${ }^{(10)}$ apenas no sudeste, onde há grande concentração de instituições de saúde reconhecidas nacionalmente pela qualidade de atendimento, universidades de prestígio nacional e internacional, e alto contingente de profissionais da saúde, a taxa de mortalidade é acima de $46 \%$ da média nacional segundo dados do Ministério da Saúde, atualizados até agosto $2013 .{ }^{(3)}$

A estratégia para reduzir significativamente o número de pessoas que vão a óbito por sepse, ainda é a prevenção, apesar de ainda não existir uma terapia efetiva anti-sepse. ${ }^{(14)} \mathrm{A}$ prevenção pode ser conquistada através da educação à população em geral através da conscientização da importância da higienização das mãos. ${ }^{(15)}$ Entretanto, se a adesão a essa medida ainda é falha entre os profissionais de saúde, que obrigatoriamente deveriam realizar o procedimento durante vários momentos ao atender o paciente,$^{(16,17)}$ esperar que o público leigo o faça seria uma 
estratégia fraca, com perda de esforços e tempo significativo.

Por isso, que concomitante à campanha de higienização das mãos, a necessidade do trabalho de conscientização de massas deve ser planejado e exige continuidade em longo prazo. Como exemplo, são inúmeras campanhas de prevenção de doenças sexualmente transmissíveis, principalmente em relação à AIDS, mesmo em tempos de acesso à informação de modo ilimitado praticamente, ainda se torna necessário abordar campanhas de prevenção e conscientização. Dessa forma, o Instituto Latino-Americano de Sepse em conjunto a diversos órgãos reguladores da saúde no Brasil, com o apoio também de instituições internacionais com o foco em sepse, tem intensificado a educação ao público para o reconhecimento do início dos sinais e sintomas e a necessidade de procurar atendimento médico, de forma a diminuir o tempo de exposição aos patógenos e à própria resposta do organismo com a cascata inflamatória, e com isso, tentar interferir no agravamento do quadro. ${ }^{(10)}$

Não apenas o público deve saber, mas o profissional responsável pelo tratamento, conforme demonstrado em um levantamento entre diversos países quanto à avaliação teórica de médicos em relação à definição correta da sepse é passível de melhoria. ${ }^{(18)} \mathrm{E}$ se fora do Brasil é possível encontrar esse tipo de resultado, em uma avaliação realizada por um grupo brasileiro, entre 21 instituições hospitalares, sendo 17 localizadas em capitais e quatro em cidades interioranas, quanto aos conceitos de sepse e de sepse grave ficam a desejar. Dada a dificuldade em se reconhecer a disfunção do órgão propriamente dito, e a deficiência no conhecimento em correlacionar a presença da disfunção orgânica com o aspecto mais grave da sepse. ${ }^{(19)}$

Embora pareça simples definir conceitos, o que foi proposto primariamente pelo American College of Chest Physicians (ACCP)/Society of Critical Care Medicine (SCCM) em 1992, ${ }^{(20)}$ levantou questionamentos, gerando a necessidade de uma segunda conferência em 2001, ${ }^{(21)}$ com a tentativa de aumentar a especificidade, com o acréscimo de sinais e sintomas comumente encontrados nos pacientes sépticos. Entretanto, a definição primária é continuamente utilizada, e melhor consolidada entre as equipes de saúde. ${ }^{(10)}$

Portanto, se dentre os prescritores há dificuldade, outros membros da equipe multiprofissional também podem apresentar essa dificuldade de reconhecimento do paciente com sepse ou sepse grave, o que possivelmente impacta 
no atendimento ao paciente que exige atenção intensiva. Sendo assim, a necessidade de programas de educação continuada entre os profissionais da saúde deve ser alvo constante para a conquista de um atendimento efetivo ao paciente que apresenta o quadro de sepse.

\subsection{Sepse: definições, protocolos, indicadores de qualidade}

A sepse tem sido definida, independente da causa da infecção local (vírus, bactéria, fungo ou protozoários), como o modo que o organismo responde sistemicamente, em diferentes estágios clínicos de um mesmo processo

fisiopatológico. ${ }^{(10,11,14,22)}$ Dessa forma, torna-se um desafio ao médico responsável pelo atendimento devido à necessidade de agilidade, tanto no reconhecimento precoce e início do tratamento o quanto antes. Pois, o tempo é crucial a esses pacientes, já que a presença de qualquer disfunção sem mesmo uma efetiva causa identificável sempre levanta a possibilidade de sepse. ${ }^{(14)}$

Para auxiliar no reconhecimento de sepse, o consenso de 1992, baseia-se na definição entre os quatro principais aspectos, em ordem de gravidade respectivamente: síndrome da resposta inflamatória sistêmica (SIRS - Systemic Inflammatory Response Syndrome), sepse, sepse grave e choque séptico. ${ }^{(20)}$

Do qual, na SIRS a presença de pelo menenos dois sintomas ou mais, é fator independente de aumento do risco de mortalidade em $26 \%$, conforme demonstrado em um estudo multicêntrico na Austrália e Nova Zelândia: ${ }^{(23)}$ temperatura central maior $38,30 \mathrm{C}$ ou menor $36^{\circ} \mathrm{C}$; frequência cardíaca maior 90 batimentos por minuto; frequência respiratória maior que 20 movimentos por minuto ou $\mathrm{PaCO}_{2}$ menor que $32 \mathrm{mmHg}$, ou necessidade de ventilação mecânica; leucócitos totais acima de 12 $\mathrm{mil} / \mathrm{mm}^{3}$ ou abaixo de $4 \mathrm{mil} / \mathrm{mm}^{3}$, ou presença maior de $10 \%$ de formas jovens. ${ }^{(20)} \mathrm{A}$ sepse é a SRIS secundária ao processo infeccioso confirmado ou suspeito, sem necessidade da identificação do agente infeccioso. A sepse grave apresenta além dos critérios de sepse a associação à disfunção orgânica e/ou sinais de hipoperfusão. ${ }^{(20,24)}$

E o choque séptico é o estado de falência circulatória aguda caracterizada pela persistência de hipotensão arterial (pressão arterial sistólica menor do que $90 \mathrm{mmHg}$, redução maior do que $40 \mathrm{mmHg}$ da linha de base, ou pressão arterial médica menor que $60 \mathrm{mmHg}$, a despeito de adequada reposição volêmica, com 
necessidade de vasopressores, na ausência de outras causas de hipotensão). ${ }^{(20)}$

Dadas as características tempo-dependente, a sepse é de importância crescente, pois fatores como aumento da população idosa, número de pacientes imunossuprimidos, transplantados, doenças crônicas, etc., ${ }^{(11,14)}$ cria-se um contingente de alertas para a susceptibilidade ao desenvolvimento de infecções graves, mesmo maximizando as medidas preventivas. Além disso, ao apresentarem tal condição grave, o manejo terapêutico é ainda mais desafiador devido às doenças de base.

Nos últimos 15 anos, o aumento da conscientização e o gerenciamento efetivo de início imediato desses pacientes teve grande impacto no desfecho clínico, entretanto, a taxa de mortalidade ainda é inaceitável. ${ }^{(11,14)}$

Em 2002, a Campanha Sobrevivendo à Sepse (Surviving Sepsis Campaign) com orientações e recomendações para o diagnóstico e o tratamento da sepse grave e do choque séptico sugerem estratégias para implementações de medidas básicas, que devem ser implementadas à beira leito. ${ }^{(4,25)} \mathrm{A}$ recomendação de tratamento foi organizada em dois pacotes: um pacote de reanimação (seis medidas para começar imediatamente e ser realizado dentro de seis horas) e um pacote de gerenciamento (quatro medidas para serem concluídas dentro de 24 horas). ${ }^{(1,25,26)}$

O pacote de reanimação de seis horas inclui a determinação do lactato para parâmetros de para reperfusão volêmica, as culturas iniciais e terapia antibiótica, logo que possível, e a "terapia precoce dirigida por metas" (EGDT - Early goal direct therapy), ${ }^{(25,26)}$ bem como um pacote de gerenciamento nas primeiras 24 horas, incluindo otimização do controle glicêmico, pois variações ao longo da internação são preditores de mortalidade, pressão de platô respiratório inspiratório, e determinação da necessidade de corticosteróides. A meta da terapia precoce direta é simplesmente um protocolo derivado de componentes que têm sido recomendados como tratamento padrão para o paciente séptico no cenário da unidade de terapia intensiva para otimização hemodinâmica ${ }^{(4)}$ mesmo com o passar do tempo ainda apresenta satisfatório impacto na taxa de mortalidade, quando gerenciado de maneira adequada. $^{(25,27)}$

Mesmo que itens como monitorização hemodinâmica central para parâmetros de administração de fluídos, uso de vasopressores, transfusões 
sanguíneas e dobutamina, não sejam contemplados no pacote de reanimação, ainda não foram encontradas evidências suficientes de benefícios ao paciente para contemplá-las no protocolo. ${ }^{(28,29)}$

Após a implementação do protocolo que exigirá da instituição algumas adequações de fluxos de atendimentos e disponibilidades de recursos humanos, indicadores a serem mensurados e acompanhados continuamente, são: tempo de disfunção orgânica, coleta do lactato nas primeiras seis horas, coleta de hemoculturas antes do início da antibioticoterapia, taxa de administração de antibiótico de amplo espectro dentro da primeira hora do diagnóstico (principalmente em pacientes atendidos no pronto socorro), tempo para antibioticoterapia, volume/vasopressor (pacientes que receberam pelo menos $30 \mathrm{~mL} / \mathrm{kg}$ de cristalóides e vasopressores, conforme indicação, para manter a pressão arterial média acima de $65 \mathrm{mmHg}$ ), taxa de monitorização da pressão venosa central, e taxa de monitorização da saturação venosa de oxigênio. ${ }^{(10,25)}$

Interessante observar que nesse pacote de tratamento dos pacientes com sepse grave e/ou choque séptico e nos indicadores de gerenciamento, não se contempla a avaliação da adequação da terapia antimicrobiana, que é uma das principais medidas de redução de mortalidade nos pacientes graves acometidos por quadro infecciosos. ${ }^{(20,30,31)}$

\subsection{Adequação da terapia antimicrobiana}

A adequação da terapia antimicrobiana é um potencial pilar de qualidade e desfecho no gerenciamento da sepse, como demonstrado previamente em uma amostra de mais de 4,9 mil pacientes internados. ${ }^{(7,32)}$ Desde as primeiras discussões para consenso entre os especialistas ao redor do mundo a respeito dos principais procedimentos para atendimento ao paciente com sepse, o reconhecimento rápido da sepse, concomitante à administração adequada da terapia antimicrobiana permanecem sem alterações e são fortemente recomendados. ${ }^{(2,14)}$

Pois, o tratamento antimicrobiano inadequado e a demora no início da antibioticoterapia estão associados ao aumento importante do risco de óbito. ${ }^{(30)}$ Apesar da necessidade de se saber exatamente o agente causador da infecção, não é recomendado aguardar a identificação do agente infeccioso para o início da 
administração do antibiótico, e quanto mais rápido ocorre para a sua administração, maior impacto na taxa de óbito, portanto, reduz a mortalidade. ${ }^{(33)}$

O que para isso, inicia-se com antibiótico com atividade ampla dos possíveis e mais comuns patógenos (bactérias Gram-negativas, Gram-positivas e/ou fungos). Antibiótico com amplo espectro não necessariamente é sinônimo de o mais potente, mas sim dentro de um racional, de acordo com a característica da infecção apresentada pelo paciente, como por exemplo, infecções comunitárias ou associadas à assistência a saúde, sítio provável da infecção, uso prévio de antibiótico, e presença de fatores de risco para infecções por microrganismos multirresistentes ou fungos. ${ }^{(10)}$

Assim que identificado o perfil do microrganismo e a sua sensibilidade antimicrobiana, como resultado primário da positividade da cultura, deve-se imediatamente ajustar o tratamento, estreitando o espectro antimicrobiano. ${ }^{(1,7-}$ 10) O que auxilia na diminuição do desenvolvimento de infecções multirresistentes, conforme identificado em uma análise prévia da instituição, $60 \%$ dos pacientes diagnosticados com sepse grave e choque séptico eram de outros setores do hospital e não do pronto atendimento, aumentando a chance de uma infecção por agentes resistentes a antimicrobianos, ${ }^{(6)} \mathrm{e}$ assim, com impacto na mortalidade intrahospitalar, dado a dificuldade no manejo de drogas efetivas e de suas toxicidades, além das doenças de base comumente apresentados pelos pacientes hospitalizados. ${ }^{(7,8,11)}$ Outros fatores associados ao uso de antibiótico inadequado é toxicidade desnecessária devido aos aspectos de farmacocinética e farmacodinâmica, bem como o custo envolvido em cada dosagem. ${ }^{(10)}$

Outro agravante, que torna a sepse ainda mais complexa para o tratamento efetivo está no fato do constante crescimento de casos de resistência bacteriana, tornando a escolha do antibiótico cada vez mais limitada, e assim, como o alto impacto no custo do tratamento. ${ }^{(10)}$

\subsection{Perfil microbiológico e mecanismos de resistência}

O desafio maior para um correto perfil microbiológico começa com a coleta da amostra. É desejável a coleta próximo ao pico febril para melhor sensibilidade, entretanto, aguardar esse momento, pode ser traduzido como retardo 
de tempo para a administração do antibiótico. A hemocultura é apenas um dos possíveis sítios do foco infeccioso, conforme a história do paciente torna-se necessário a coleta de espécimes de secreção do trato respiratório, urocultura, secreções de abcessos ou coleções de feridas, líquidos articulares, pontas de cateteres, líquor, dentre outros. ${ }^{(10,32)}$

Staphylococcus aureus e Streptococcus pneumoniae são os microrganismos mais comuns dentre os Gram-positivos isolados. E dentre os Gramnegativos, Esche- richia coli, Klebsiella spp, e Pseudomonas aeruginosa são os mais identificados. ${ }^{(1,32)}$

Entre 1979 a 2000, infecções por bactérias Gram-positivas eram mais prevalentes. Atualmente, em um estudo que envolveu 14 mil pacientes graves, em 75 países, as bactérias Gram-negativas foram isoladas em $62 \%$ dos exames positivos de culturas realizadas, conforme demonstrado pelo estudo EPIC II (European Prevalence of Infection in Intensive Care), sendo $47 \%$ por bactérias Gram-positivas, e $19 \%$ fungos. ${ }^{(1,32)}$

Conforme resultado de uma meta-análise envolvendo 510 estudos, bacteriemia causada por bactérias Gram-negativas estava associada à alta mortalidade comparada a infecções por bactérias Gram-positivas. ${ }^{(34)}$

A classificação positiva ou negativa disponível de Gram pode-se sugerir certa facilidade de intervenção, porém com o passar do tempo, e o uso inadequado dos antibióticos, foi possível observar dentre essas bactérias mecanismos adaptativos, que Ihes conferiu resistência aos antimicrobianos. ${ }^{(6)}$

Por exemplo, nas bactérias Gram-negativas, a principal causa de resistência aos beta-lactâmicos mais recentes (cefalosporinas de amplo espectro, e o aztreonam) é através da produção de beta-lactamases de espectro ampliado (ESBL), mediadas por plasmídeos e originando-se através de mutações de enzimas específicas da bactéria. São produzidas, principalmente pela Escherichia coli e Klebsiella pneumoniae, com prevalência que chega a $52 \% .{ }^{(35)}$

Ainda dentre as bactérias Gram-negativas, a Pseudomona aeruginosa é um dos patógenos que demonstra adquirir resistência a todos os antibióticos, através de hiper-produção de beta-lactamases, alteração de porinas, bomba de efluxo, metalo-beta-lactamases, redução de afinidade (topoisomerases II e IV), redução do transporte aos aminoglicosídeos, alteração da membrana externa, e atualmente apresenta alta taxa de resistência aos carbapenens. ${ }^{(36)}$ 
Dentre as principais bactérias Gram-positivas estão os coccus, sendo o Staphylococcus aureus, identificado na década de 60, como patógeno nosocomial resistente à meticilina/oxacilina (MRSA/ORSA, respectivamente), atualmente não apenas a essas drogas, como também a todos os antibióticos beta-

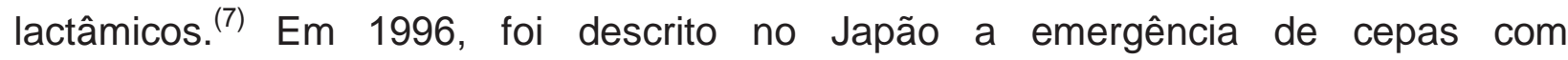
sensibilidade intermediária à vancomicina (VISA), ${ }^{\left({ }^{37}\right)}$ e em 2002, em Michigan foi descrito o primeiro caso de resistência à vancomicina (VRSA). ${ }^{(38)}$

Outra bactéria isolada frequentemente em materiais clínicos, que pode apresentar resistência é o Enterococcus (como exemplo, as espécies faecalis e faecium) em relação à vancomicina (VRE). ${ }^{(7)}$ 


\section{MÉTODOS}

Foi realizado um estudo descritivo, retrospectivo (período de 2005 a 2012), na unidade de terapia intensiva adulto do Hospital Israelita Albert Einstein, uma instituição privada de atendimento terciário, com foco em alta complexidade. Apresenta 617 leitos, localizado na cidade de São Paulo, Brasil.

A sepse foi definida como infecção, com dois ou mais dos seguintes critérios da Síndrome da Resposta Inflamatória Sistêmica: temperatura (T) $>38^{\circ} \mathrm{C}$ ou $<36^{\circ} \mathrm{C}$, frequência cardíaca $(\mathrm{FC})>90$ batimentos por minuto, frequência respiratória (FR) 20 ciclos por minuto (ou $\mathrm{PaCO}_{2}<32 \mathrm{mmHg}$ ), ou contagem de leucócitos $>12.000$ células $/ \mathrm{mL}$ ou $<4.000$ células $/ \mathrm{mL}^{(20)}$

A sepse grave foi definida como: sepse mais disfunção orgânica, hipotensão, hipoperfusão ou anormalidades, incluindo acidose láctica, oligúria ou encefalopatia. O choque séptico: sepse com hipotensão induzida, onde há uma pressão arterial sistólica (PAS) $<90 \mathrm{mmHg}$, ou uma redução de $>40 \mathrm{mmHg}$, na ausência de outras causas de hipotensão, concomitante às anormalidades de hipoperfusão, apesar da reposição adequada de volume endovenoso. ${ }^{(20)}$

Identificada as características da sepse grave ou choque séptico, outro critério de inclusão foi relacionada à idade, maior ou igual a 18 anos no dia da admissão. Dessa forma, os dados coletados para a análise foram: sexo, tempo de permanência, data e hora do diagnóstico de sepse grave ou choque séptico, local de internação antes da transferência à Unidade de Terapia Intensiva, presença de disfunção de órgãos no momento do diagnóstico, através de relatos descritos em prontuário e o escore de avaliação Acute Physiology and Chronic Health Evaluation (APACHE) II.

O tratamento foi conduzido de acordo com o preconizado pela diretriz internacional ${ }^{(4)}$ uma vez que o paciente apresentou um critério de iniciação do protocolo. O pacote sepse de seis horas foi iniciado com a coleta do lactato e das hemoculturas, antes da administração do antibiótico. A partir do tempo de sepse grave (tempo zero) iniciou-se o antibiótico de largo espectro no prazo de uma hora após a admissão, o tratamento da hipotensão e/ou aumento de lactato com os fluídos, em caso de hipotensão persistente apesar da reposição (choque séptico), e/ou lactato $>36 \mathrm{mg} / \mathrm{dL}$ ou $>04 \mathrm{mmol} / \mathrm{L}$, manteve-se a pressão venosa central e uma adequada 
saturação de oxigênio venoso central. Os pacientes que não tiveram choque e aumento de lactato não necessitaram de tal adequação nos parâmetros centrais.

O pacote sepse $24 \mathrm{~h}$ contempla a monitorização da glicose entre $\geq 70 \mathrm{mg} / \mathrm{dL}$ a $<150 \mathrm{mg} / \mathrm{dL}$, e pressão de platô inspiratório médio (IPP)<30cm H20 para pacientes em ventilação mecânica. Os critérios de conformidade para corticosteroides foi administrar $300 \mathrm{mg} / \mathrm{dia}$ de hidrocortisona intravenosa durante sete dias, divididas em três doses, aos pacientes com hipotensão refratária apesar das medidas de reposição volêmica e das doses das drogas vasopressoras. A condição clínica de cada paciente foi avaliada com critérios previamente publicados pelo American College of Chest Physicians/Society of Critical Care Medicine (ACCP/SCCM)20.

O Hospital Israelita Albert Einstein dispõe de um sistema eletrônico, chamado "tecla sepse" para ativação de uma equipe dedicada para diagnosticar e tratar todos os casos suspeitos de sepse grave e choque séptico imediatamente, que abrange toda a instituição, principalmente nos locais onde não há disponibilidade de médicos 24 horas por dia. Além desse serviço de atendimento rápido, outro semelhante, é o de emergência e urgência, nomeado de "código amarelo". (39)

O "Código Amarelo" tem os seguintes critérios para ser acionado: problemas respiratórios como diminuição aguda na saturação de oxigênio $<90 \%$ e mudança de FR <8 ou >28 ciclos por minuto; problemas circulatórios: diminuição da PAS $<90 \mathrm{mmHg}$, associada a sintomas e alterações na FC <40 ou >130 batimentos por minuto; problemas neurológicos: diminuição dos níveis de consciência e convulsões, ou quando a avaliação do enfermeiro "estar seriamente preocupado com o estado geral do paciente", ou o paciente relatou "algo não está certo". Alguns desses sinais são os mesmos dos diagnosticados em pacientes com sepse. ${ }^{(39)}$

\subsection{Terapêutica antimicrobiana}

O uso de antibiótico foi considerado adequado, se utilizado pelo menos um dos antibióticos ao qual a bactéria identificada na hemocultura era sensível "in vitro" até $24 \mathrm{~h}$ após a coleta da cultura. ${ }^{(7,10)}$

Se o microrganismo isolado não fosse sensível "in vitro" ao antibiótico utilizado, a terapia foi considerada inadequada. ${ }^{(7)} \mathrm{O}$ laboratório de 
microbiologia do Hospital Israelita Albert Einstein possui um sistema de alerta para notificação dos médicos responsáveis pelo paciente do resultado positivo da hemocultura, bem como os resultados da coloração de Gram.

\subsection{Métodos microbiológicos}

Todas as amostras foram identificadas pelo método manual ou automatizado e confirmado usando o sistema Vitek 2 (bio-Vitek Merieux, Inc., Hazelwood, MO). Para a determinação da porcentagem de resistência antimicrobiana, os mesmos microrganismos a partir de culturas de sangue ou várias da mesma fonte, com perfil antimicrobiano idêntico foram considerados a de um único isolado.

Testes de susceptibilidade antimicrobiano dos isolados dos pacientes com sepse grave e choque séptico foram realizados pelo método automatizado considerado anteriormente ou pelo método de disco difusão como descrito pelo Clinical and Laboratory Standards Institute (CLSI). ${ }^{(40)}$

Foi considerado como bactérias pertencentes ao grupo ESKAPE os resultados de crescimento positivo nas hemoculturas com os seguintes achados: Enterococcus faecium, Staphylococcus aureus, Klebsiella pneumoniae, Acinetobacter baumannii, Pseudomonas aeruginosa, e Enterobacter spp.

\subsection{Análise estatística}

As diferenças ao longo do tempo foram avaliadas por modelos de séries temporais auto-regressivos. A ordem dos modelos foi determinada de acordo com a análise da função de auto-correlação parcial de resíduos. O resumo do ano foi apresentado como média \pm desvio padrão ou frequências absolutas e percentuais. $A$ significância das mudanças foi avaliada por efeitos de tendência. Todos os testes de significância foram bi-caudados e o nível de alfa foi fixado em 0,05.

Para analisar o impacto da terapia antimicrobiana inadequada sobre a mortalidade nos 358 pacientes com infecção de corrente sanguínea, os modelos foram construídos por meio de regressão logística binária em abordagens simples e múltiplas, apenas com dados coletados entre 2010 e 2012. As variáveis com $p \leq 0,10$ na 
análise dos modelos simples foram avaliadas por meio de multivariada. A associação das variáveis independentes foi expressa como odds ratio (razão de chances) com intervalo de confiança de $95 \%$.

As análises foram realizadas com o programa Statistical Package for the Social Sciences (SPSS) 17.0 (Chicago, IL, EUA). 


\section{RESULTADOS}

A amostra total (Tabela 1), foi composta por 1.279 pacientes consecutivos com sepse grave ou choque séptico, onde $57,7 \%(n=738)$ foram do sexo masculino, idade média de $67 \pm 18$ anos, APACHE II médio de $18 \pm 10$, tempo médio de permanência de $33 \pm 71$ dias, tempo médio para administração do antibiótico foi de 2,5 $\pm 3,6$ horas, valor médio do lactato de $27 \pm 24 \mathrm{mg} / \mathrm{dL}$, saturação venosa de oxigênio $76,2 \pm 11,4$, e os casos de óbitos foram 371 (29,0\%) pacientes.

Tabela 1. Características demográficas e clínicas dos pacientes com sepse grave e choque séptico

\begin{tabular}{lcc}
\hline Variáveis & $\mathbf{N}$ & ( $\%)$ \\
\hline Masculino & 738 & 57,7 \\
Ano & & \\
2005 & 75 & 5,9 \\
2006 & 106 & 8,3 \\
2007 & 136 & 10,6 \\
2008 & 129 & 10,1 \\
2009 & 123 & 9,6 \\
2010 & 195 & 15,3 \\
2011 & 237 & 18,5 \\
2012 & 278 & 21,7 \\
Disfunção & & \\
Hepática & 68 & 5,3 \\
Circulatória & 882 & 69,0 \\
Renal & 511 & 40,0 \\
Hematológica & 462 & 36,1 \\
Respiratória & 831 & 65,0 \\
Neurológica & 425 & 33,2 \\
Nenhuma disfunção orgânica & 236 & 18,5 \\
Apresentaram até quatro disfunções orgânicas & 955 & 74,7 \\
Apresentaram cinco ou mais disfunções & 88 & 6,9 \\
Acidose metabólica durante a internação & 461 & 36,0 \\
Receberam antibiótico até 1 hora & 791 & 61,8 \\
Coleta lactato & 1234 \\
Hipolactatemia ou hiperlactatemia & 1217 & 96,5 \\
Valor do lactato maior que 36mg/dL & 249 & 98,6 \\
Coleta da saturação venosa central & 748 & 20,2 \\
Mortalidade Intra-hospitalar & 371 & 58,5 \\
Prescrição para realizar a hemocultura & 1117 & 29,0 \\
Crescimento positivo & 358 \\
Polimicrobiano (N=358) & 25 & 32,1 \\
Adequação do antibiótico (N=358) & 260 \\
\hline & & 72,6 \\
\hline
\end{tabular}


$\mathrm{Na}$ comparação do pacote sepse (Tabela 2), houve aumento progressivo da coleta de lactato, prescrição das hemoculturas, antibiótico em até uma hora e uso de antibiótico adequado com diferença significante na comparação entre 2010, 2011 e 2012. Observou-se também a queda na taxa da mortalidade hospitalar com diferença significante entre esses anos.

Tabela 2. Análise da comparação dos itens do pacote sepse entre os anos de 2010, 2011 e 2012

\begin{tabular}{|c|c|c|c|c|c|c|c|}
\hline \multirow{3}{*}{ Variáveis } & \multicolumn{6}{|c|}{ Ano do diagnóstico } & \multirow{3}{*}{ Valor-p } \\
\hline & \multicolumn{2}{|c|}{$\begin{array}{c}2010 \\
(n=197)\end{array}$} & \multicolumn{2}{|c|}{$\begin{array}{c}2011 \\
(n=240)\end{array}$} & \multicolumn{2}{|c|}{$\begin{array}{c}2012 \\
(n=279)\end{array}$} & \\
\hline & $\mathbf{n}$ & $\%$ & n & $\%$ & $\mathbf{N}$ & $\%$ & \\
\hline Choque séptico & 116 & 58,9 & 152 & 63,3 & 182 & 65,2 & 0,362 \\
\hline Coleta lactato & 183 & 92,9 & 231 & 96,3 & 274 & 98,2 & 0,013 \\
\hline $\begin{array}{l}\text { Prescrição para realizar as } \\
\text { hemoculturas }\end{array}$ & 171 & 86,8 & 232 & 96,7 & 270 & 96,8 & $<0,001$ \\
\hline Antibiótico até 1 hora & 105 & 53,3 & 137 & 57,1 & 228 & 81,7 & $<0,001$ \\
\hline Coleta da saturação venosa central & 62 & 31,5 & 130 & 54,2 & 159 & 57,0 & $<0,001$ \\
\hline \multirow{2}{*}{$\begin{aligned} & \text { Valor da saturação de oxigênio venosa* }> \\
& \geq\end{aligned}$} & 03 & 4,8 & 30 & 23,1 & 56 & 35,2 & $<0,001$ \\
\hline & 59 & 95,2 & 100 & 76,9 & 103 & 64,8 & \\
\hline Óbito & 61 & 31,0 & 46 & 19,2 & 49 & 17,6 & 0,001 \\
\hline Antibiótico adequado* & 40 & 76,9 & 52 & 69,3 & 59 & 81,9 & 0,198 \\
\hline Idade - Média (Desvio padrão) & \multicolumn{2}{|c|}{$69 \pm 19$} & \multicolumn{2}{|c|}{$67 \pm 18$} & \multicolumn{2}{|c|}{$66 \pm 18$} & 0,222 \\
\hline
\end{tabular}

Dentre os fatores de risco na tabela 3, quanto maior o valor do APACHE II, maior a chance de óbito. Os pacientes com disfunção circulatória, renal, hematológica, respiratória também apresentaram maior chance de óbito. Com menor chance de óbito foram os pacientes que tiveram coletados os exames de hemocultura, lactato e saturação venosa central. 
Tabela 3. Análise dos fatores de risco para mortalidade hospitalar para os pacientes com sepse grave ou choque séptico

\begin{tabular}{|c|c|c|c|c|c|c|c|c|}
\hline \multirow{3}{*}{ Variáveis } & \multicolumn{4}{|c|}{ Univariada } & \multicolumn{4}{|c|}{ Multivariada } \\
\hline & \multirow{2}{*}{$\begin{array}{l}\text { Odds } \\
\text { ratio }\end{array}$} & \multicolumn{2}{|c|}{$\begin{array}{l}\text { 95\% Intervalo } \\
\text { de confiança }\end{array}$} & \multirow[t]{2}{*}{ Valor-p } & \multirow{2}{*}{$\begin{array}{l}\text { Odds } \\
\text { ratio }\end{array}$} & \multicolumn{2}{|c|}{$\begin{array}{l}95 \% \text { Intervalo } \\
\text { de confiança }\end{array}$} & \multirow[t]{2}{*}{ Valor-p } \\
\hline & & Min. & Máx. & & & Min. & Máx. & \\
\hline Idade & 1,010 & 1,003 & 1,017 & 0,004 & 1,004 & 0,997 & 1,012 & 0,263 \\
\hline "APACHE II & 1,060 & 1,046 & 1,074 & $<0,001$ & 1,052 & 1,037 & 1,067 & $<0,001$ \\
\hline Disfunção hepática & 1,021 & 0,597 & 1,745 & 0,940 & & & & \\
\hline Disfunção circulatória & 1,797 & 1,360 & 2,376 & $<0,001$ & 1,439 & 1,048 & 1,976 & 0,025 \\
\hline Disfunção renal & 2,391 & 1,869 & 3,060 & $<0,001$ & 1,792 & 1,371 & 2,341 & $<0,001$ \\
\hline $\begin{array}{l}\text { Disfunção } \\
\text { hematológica }\end{array}$ & 1,405 & 1,096 & 1,800 & 0,007 & 1,684 & 1,270 & 2,234 & $<0,001$ \\
\hline Disfunção respiratória & 1,267 & 0,979 & 1,640 & 0,072 & 1,693 & 1,265 & 2,266 & $<0,001$ \\
\hline Disfunção neurológica & 1,369 & 1,064 & 1,762 & 0,015 & 1,286 & 0,976 & 1,694 & 0,073 \\
\hline $\begin{array}{l}\text { Hemoculturas } \\
\text { coletadas }\end{array}$ & 0,316 & 0,226 & 0,442 & $<0,001$ & 0,380 & 0,264 & 0,546 & $<0,001$ \\
\hline $\begin{array}{l}\text { Administração de } \\
\text { antibiótico } \\
\text { até } 1 \text { hora }\end{array}$ & 0,689 & 0,539 & 0,881 & 0,003 & 0,771 & 0,589 & 1,010 & 0,060 \\
\hline Coleta de lactato & 0,452 & 0,249 & 0,823 & 0,009 & 1,383 & 1,037 & 1,845 & 0,027 \\
\hline $\begin{array}{l}\text { Coleta de } \\
\text { saturação venosa } \\
\text { central }\end{array}$ & 1,850 & 1,433 & 2,389 & $<0,001$ & 0,392 & 0,203 & 0,757 & 0,005 \\
\hline
\end{tabular}

*: APACHE II: Acute Physiology and Chronic Health Evaluation II.

$\mathrm{Na}$ tabela 4, observou-se por meio do modelo de regressão logística, que quanto maior o valor de APACHE II dos pacientes, maior era a chance de óbito. Pacientes com disfunção renal e neurológica apresentaram maiores chances de óbito. Quanto maior a adequação antimicrobiana pela hemocultura, menor era a chance de óbito. 
Tabela 4. Análise dos fatores de risco para mortalidade hospitalar para pacientes com sepse grave ou choque séptico que apresentaram infecção da corrente sanguínea

\begin{tabular}{|c|c|c|c|c|c|c|c|c|}
\hline \multirow{3}{*}{ Variáveis } & \multicolumn{4}{|c|}{ Univariada } & \multicolumn{4}{|c|}{ Multivariada } \\
\hline & \multirow{2}{*}{$\begin{array}{l}\text { Odds } \\
\text { ratio }\end{array}$} & \multicolumn{2}{|c|}{$\begin{array}{l}\text { 95\% Intervalo } \\
\text { de confiança }\end{array}$} & \multirow[t]{2}{*}{ Valor-p } & \multirow{2}{*}{$\begin{array}{l}\text { Odds } \\
\text { ratio }\end{array}$} & \multicolumn{2}{|c|}{$\begin{array}{l}\text { 95\% Intervalo } \\
\text { de confiança }\end{array}$} & \multirow[t]{2}{*}{ Valor-p } \\
\hline & & Min. & Máx. & & & Min. & Máx. & \\
\hline Idade (anos) & 0,996 & 0,983 & 1,009 & 0,521 & & & & \\
\hline $\begin{array}{l}\text { *APACHE II na } \\
\text { UTI }\end{array}$ & 1,041 & 1,017 & 1,066 & 0,001 & 1,029 & 1,004 & 1,055 & 0,022 \\
\hline $\begin{array}{l}\text { Disfunção } \\
\text { hepática }\end{array}$ & 1,078 & 0,456 & 2,547 & 0,865 & & & & \\
\hline $\begin{array}{l}\text { Disfunção } \\
\text { circulatória }\end{array}$ & 1,778 & 0,985 & 3,208 & 0,056 & 1,392 & 0,746 & 2,595 & 0,299 \\
\hline Disfunção renal & 2,815 & 1,754 & 4,518 & $<0,001$ & 2,432 & 1,472 & 4,018 & 0,001 \\
\hline $\begin{array}{l}\text { Disfunção } \\
\text { hematológica }\end{array}$ & 1,517 & 0,949 & 2,425 & 0,082 & 1,583 & 0,953 & 2,628 & 0,076 \\
\hline $\begin{array}{l}\text { Disfunção } \\
\text { respiratória }\end{array}$ & 1,480 & 0,917 & 2,387 & 0,108 & & & & \\
\hline $\begin{array}{l}\text { Disfunção } \\
\text { neurológica }\end{array}$ & 1,987 & 1,234 & 3,200 & 0,005 & 1,908 & 1,153 & 3,158 & 0,012 \\
\hline $\begin{array}{l}\text { Administração de } \\
\text { antibiótico até } 1 \\
\text { hora } \\
\text { Adequação }\end{array}$ & 0,887 & 0,554 & 1,420 & 0,618 & & & & \\
\hline $\begin{array}{l}\text { antimicrobiana } \\
\text { pelas } \\
\text { hemoculturas }\end{array}$ & 0,505 & 0,308 & 0,829 & 0,007 & 0,536 & 0,314 & 0,916 & 0,023 \\
\hline Coleta de lactato & 0,481 & 0,127 & 1,829 & 0,283 & & & & \\
\hline $\begin{array}{l}\text { Coleta de } \\
\text { saturação } \\
\text { venosa central }\end{array}$ & 1,411 & 0,859 & 2,317 & 0,174 & & & & \\
\hline
\end{tabular}

Quanto aos fatores de risco para a inadequação antimicrobiana, (Tabela 5), foram indicados: gênero masculino (28,5\%); disfunções como hepática $(18,5 \%)$, respiratória $(26,2 \%)$, renal $(26,8 \%)$, neurológica $(26,9 \%)$, circulatória $(28,6 \%)$ e hematológica (29,1\%); acidose metabólica durante a internação $(29,3 \%$ ), presença de alguma bactéria do ESKAPE (Enterococcus faecium, Staphylococcus aureus, Klebsiella pneumoniae, Acinetobacter baumannii, Pseudomonas aeruginosa, e Enterobacter spp) (33,3\%), perfil polimicrobiano (48,0\%), média de idade foi de $65 \pm 20$ e o APACHE II médio foi de $21 \pm 11$. 
Tabela 5. Descrição dos fatores de risco em relação à inadequação antimicrobiana dos pacientes com sepse grave ou choque séptico que tiveram infecção da corrente sanguínea

\begin{tabular}{|c|c|c|c|c|}
\hline \multirow{3}{*}{ Variáveis } & \multicolumn{4}{|c|}{$\begin{array}{l}\text { Adequação ao antibiótico } \\
\qquad(\mathrm{N}=358)\end{array}$} \\
\hline & \multicolumn{2}{|c|}{$\begin{array}{c}\text { Não } \\
(\mathrm{N}=98)\end{array}$} & \multicolumn{2}{|c|}{$\begin{array}{c}\text { Sim } \\
(N=260)\end{array}$} \\
\hline & $\mathbf{N}$ & $\%$ & $\mathbf{N}$ & $\%$ \\
\hline Masculino & 63 & 64,3 & 158 & 60,8 \\
\hline Disfunção hepática & 05 & 5,1 & 22 & 8,5 \\
\hline Disfunção circulatória & 78 & 79,6 & 195 & 75,0 \\
\hline Disfunção renal & 37 & 37,8 & 101 & 38,8 \\
\hline Disfunção hematológica & 39 & 39,8 & 95 & 36,5 \\
\hline Disfunção respiratória & 55 & 56,1 & 155 & 59,6 \\
\hline Disfunção neurológica & 32 & 32,7 & 87 & 33,5 \\
\hline Acidose metabólica durante a internação & 39 & 39,8 & 94 & 36,2 \\
\hline Bacteriemia polimicrobiana & 12 & 12,2 & 13 & 5,0 \\
\hline Presença de alguma bactéria do *ESKAPE & 44 & 44,9 & 88 & 33,8 \\
\hline Idade (média, DP) & \multicolumn{2}{|c|}{$65 \pm 20$} & \multicolumn{2}{|c|}{$64 \pm 17$} \\
\hline *APACHE II (média, DP) & \multicolumn{2}{|c|}{$21 \pm 11$} & \multicolumn{2}{|c|}{$17 \pm 10$} \\
\hline
\end{tabular}

Na tabela 6, observa-se que quanto maior o valor de APACHE II e a presença de bacteriemia polimicrobiana, maior a chance de inadequação antimicrobiana com diferença estatisticamente significante.

Tabela 6. Análise dos fatores de risco para a inadequação antimicrobiana dos pacientes com sepse grave ou choque séptico que tiveram infecção da corrente sanguínea

\begin{tabular}{|c|c|c|c|c|c|c|c|c|}
\hline \multirow{3}{*}{ Variáveis } & \multicolumn{4}{|c|}{ Univariada } & \multicolumn{4}{|c|}{ Multivariada } \\
\hline & \multirow{2}{*}{$\begin{array}{l}\text { Odds } \\
\text { ratio }\end{array}$} & \multicolumn{2}{|c|}{$\begin{array}{l}\text { 95\% Intervalo } \\
\text { de confiança }\end{array}$} & \multirow{2}{*}{ Valor-p } & \multirow{2}{*}{$\begin{array}{l}\text { Odds } \\
\text { ratio }\end{array}$} & \multicolumn{2}{|c|}{$\begin{array}{l}95 \% \text { Intervalo } \\
\text { de confiança }\end{array}$} & \multirow{2}{*}{ Valor-p } \\
\hline & & Min. & Máx. & & & Min. & Máx. & \\
\hline Masculino & 1,162 & 0,717 & 1,882 & 0,542 & & & & \\
\hline Idade & 1,005 & 0,991 & 1,018 & 0,495 & & & & \\
\hline *APACHE II & 1,044 & 1,02 & 1,069 & $<0,001$ & 1,048 & 1,023 & 1,074 & $<0,001$ \\
\hline Disfunção hepática & 0,582 & 0,214 & 1,581 & 0,288 & & & & \\
\hline Disfunção circulatória & 1,300 & 0,738 & 2,289 & 0,363 & & & & \\
\hline Disfunção renal & 0,955 & 0,592 & 1,541 & 0,850 & & & & \\
\hline $\begin{array}{l}\text { Disfunção } \\
\text { hematológica }\end{array}$ & 1,148 & 0,713 & 1,849 & 0,570 & & & & \\
\hline Disfunção respiratória & 0,866 & 0,542 & 1,386 & 0,550 & & & & \\
\hline $\begin{array}{l}\text { Disfunção } \\
\text { neurológica }\end{array}$ & 0,964 & 0,588 & 1,581 & 0,885 & & & & \\
\hline $\begin{array}{l}\text { Bacteriemia } \\
\text { polimicrobiana }\end{array}$ & 2,651 & 1,165 & 6,032 & 0,020 & 2,954 & 1,227 & 7,115 & 0,016 \\
\hline $\begin{array}{l}\text { Presença de } \\
\text { alguma bactéria do } \\
{ }^{*} \text { ESKAPE }\end{array}$ & 1,593 & 0,992 & 2,558 & 0,054 & 1,436 & 0,872 & 2,366 & 0,155 \\
\hline
\end{tabular}


Para avaliação do perfil microbiológico verificou-se que dentre as 1.117 hemoculturas realizadas, apenas 358 apresentaram crescimento positivo para algum microrganismo.

Do total das 358 hemoculturas positivas, 333 (93,0\%) hemoculturas apresentaram o crescimento de apenas um microrganismo, e 25 $(7,0 \%)$ apresentaram hemoculturas com crescimento polimicrobiano, sendo que 24 amostras com crescimento de duas bactérias, e em um resultado foi possível identificar três bactérias diferentes (Streptococcus anginosus, Enterobacter aerogenes e Enterococcus faecalis). Foi possível identificar o perfil de sensibilidade aos antibióticos de 382 microrganismos diferentes.

Dentre os 382 microrganismos identificados, a Escherichia coli apareceu em 28,5\% ( $\mathrm{N}=109)$ do total. Na sequência, Streptococcus pneumoniae em $8,1 \%(\mathrm{~N}=31)$ dos casos, foi possível identificar todas as bactérias pertencentes ao grupo ESKAPE: Enterococcus faecium em 0,8\% ( $\mathrm{N}=03)$ dos casos, Staphylococcus aureus em $6,3 \%(\mathrm{~N}=24)$ dos casos, Klebsiella pneunomiae em 6,0\% ( $\mathrm{N}=23)$ dos casos, Acinetobacter baumannii em $1,0 \%(\mathrm{~N}=04)$ dos casos e Pseudomonas aeruginosa em $6,0 \%(\mathrm{~N}=23)$ dos casos, conforme tabela 7 .

A título de análise das bactérias mais prevalentes, para facilitar a análise foram agrupados na categoria "outros" como os achados de bactérias identificadas apenas uma vez, ao longo de todo o estudo. 
Tabela 7. Perfil microbiológico identificados nas hemoculturas com crescimento de microrganismos dos pacientes com sepse grave ou choque séptico

\begin{tabular}{|c|c|c|}
\hline Microrganismos & $\mathbf{N}$ & $\%$ \\
\hline Escherichia coli & 109 & 28,5 \\
\hline Streptococcus pneumoniae & 31 & 8,1 \\
\hline Staphylococcus epidermidis & 29 & 7,6 \\
\hline Staphylococcus aureus & 24 & 6,3 \\
\hline Klebsiella pneumoniae & 23 & 6,0 \\
\hline Pseudomonas aeruginosa & 23 & 6,0 \\
\hline Enterococcus faecalis & 13 & 3,4 \\
\hline Streptococcus pyogenes (Grupo A) & 09 & 2,4 \\
\hline Enterobacter cloacae & 08 & 2,1 \\
\hline Staphylococcus capitis & 07 & 1,8 \\
\hline Staphylococcus haemolyticus & 06 & 1,6 \\
\hline Streptococus agalactiae (Grupo B) & 06 & 1,6 \\
\hline Klebsiella oxytoca & 05 & 1,3 \\
\hline Proteus mirabilis & 05 & 1,3 \\
\hline Staphylococcus hominis & 05 & 1,3 \\
\hline Acinetobacter baumanni & 04 & 1,0 \\
\hline Acinetobacter calcoaceticus - baumanni complex & 04 & 1,0 \\
\hline Enterobacter aerogenes & 04 & 1,0 \\
\hline Salmonella spicies & 04 & 1,0 \\
\hline Serratia marcescens & 04 & 1,0 \\
\hline Aeromonas spp & 03 & 0,8 \\
\hline Candida parapsilosis & 03 & 0,8 \\
\hline Enterococcus faecium & 03 & 0,8 \\
\hline Stenotrophomonas maltophila (Xanthomonas maltophilia) & 03 & 0,8 \\
\hline Streptococcus anginosus & 03 & 0,8 \\
\hline Streptococcus gallolyticus spp pasteurianus & 03 & 0,8 \\
\hline Candida albicans & 02 & 0,5 \\
\hline Outros & 39 & 10,2 \\
\hline Total & 382 & 100,0 \\
\hline
\end{tabular}

Em relação à classificação dos microrganismos na tabela 8 , em $57,3 \%(n=219)$ dos casos foram bactérias Gram-negativas, seguido das bactérias Gram-positivas em 40,9\% ( $n=156)$ dos casos e dos fungos com 1,8\% dos achados $(\mathrm{n}=07)$.

Tabela 8. Classificação dos microrganismos identificados nas hemoculturas em que houve crescimento

\begin{tabular}{lcc}
\hline Classificação & N & $\%$ \\
\hline Gram-negativos & 219 & 57,3 \\
Gram-positivos & 156 & 40,9 \\
Fungos & 07 & 1,8 \\
\hline Total & $\mathbf{3 8 2}$ & $\mathbf{1 0 0 , 0}$ \\
\hline
\end{tabular}




\section{DISCUSSÃO}

Com a análise dos dados do protocolo gerenciado de sepse em um único centro de saúde, no Hospital Israelita Albert Einstein foi possível identificar mais de mil pacientes com as formas mais graves da sepse, que tem por característica sua alta complexidade, e exigiu da instituição o investimento para a busca das melhores evidências a serem oferecidas a estes pacientes. O perfil demográfico resultante do estudo, e demonstrado na tabela 1, é semelhante aos dados nacionais de hospitais privados apresentados no relatório do Instituto Latino-Americano para Estudos da Sepse e dados do Centers for Disease Control and Prevention, porém com a diferença que em nosso estudo, a maioria dos pacientes era do sexo masculino e mais idosa. ${ }^{(31)}$

Ao longo dos anos, com a maturidade do protocolo, semelhante ao que aconteceu com outros protocolos institucionais, ${ }^{(41)}$ e do próprio fluxo interno de reconhecimento da piora do paciente, através do atendimento do time de resposta rápida (Código Amarelo), ${ }^{(39)}$ é provável que a evolução da doença possa ter sido modificada, com o reconhecimento precoce pela equipe multi-assistencial, resultando em uma rápida intervenção terapêutica, e assim, proporcionando uma diminuição da forma mais grave da sepse, que é o choque séptico. Antes do protocolo da sepse (anterior a 2005), 88\% dos pacientes apresentavam choque séptico, sendo que em 2012, foram identificados $65,2 \%$ pacientes com choque séptico (Tabela 1 , conforme apresentado anteriormente).

Os resultados com a melhora da adesão aos itens do pacote do protocolo, ao longo dos anos, pôde indicar a melhoria da experiência dos profissionais da instituição que lidam diretamente com estados graves, como é o caso da sepse grave e do choque séptico. Além de estarem de acordo com a diretriz internacional e a Campanha Sobrevivendo à Sepse (Surviving Sepsis Campaign), estatisticamente pôde-se comprovar esse fato conforme a queda da taxa de mortalidade. ${ }^{(4)}$

Fatores de risco para óbito continuam fortemente ligados ao APACHE II, ${ }^{(42)}$ avaliado apenas no dia da admissão na unidade de terapia intensiva. O APACHE II serve de base para o indicador de prognóstico, logo que o paciente entra na unidade de terapia intensiva (como rotina), bem como a presença de outras disfunções que contribuem com a piora pronunciada do seu estado geral, conforme descrito na literatura. ${ }^{(13)}$ Uma explicação do porquê dos pacientes com maior APACHE 
II estarem associados à terapia antimicrobiana inadequada, pode estar relacionada a uma possível subestimação da gravidade desses pacientes. É possível que se fosse avaliado o escore APACHE II no momento do diagnóstico de sepse grave ou choque séptico, a sua pontuação seria muito diferente.

Em um estudo, realizado na Noruega, onde foram avaliados registros de pacientes diagnosticados com sepse comunitária, dados como etiologia, terapia antimicrobiana prescrita, e resultados pós-internação, rápida identificação da fonte infecciosa, a amostragem adequada para as análises microbiológicas, e a rápida administração da terapêutica antimicrobiana adequada foram cruciais. Não apenas ao paciente, com bons desfechos clínicos, como para a gestão do cuidado na instituição através de indicadores de desempenho e resultados. ${ }^{(43)}$

Desde o início do protocolo de sepse na instituição (no decorrer de 2005), a prática à beira leito e o contato com a medicina baseada em evidências, ${ }^{(44)}$ com diversas reuniões científicas entre a equipe multidisciplinar, contribuíram também na melhoria do atendimento a esses pacientes. Os indicadores, semelhantemente ao ocorrido na Noruega, ${ }^{(43)}$ têm trazido importante impacto na prática diária do Hospital Israelita Albert Einstein.

Ao observar esse período de análise, mudanças nas diretrizes em relação ao tratamento medicamentoso ocorreram. Por exemplo, a medicação alfa drotrecogina ativada (Xigris ${ }^{\circledR}$ ), conforme demonstrado pelo estudo PROWESS (Recombinant Human Activated Protein C Worldwide Evaluation in Severe Sepsis), a administração dessa medicação quando diagnosticado a sepse grave e/ou choque séptico significava benefício ao paciente, e, portanto, impacto na taxa de mortalidade intra-hospitalar. Essa informação foi analisada pelo estudo PROGRESS (Promoting Global Research Excellence in Severe Sepsis), ${ }^{(45)}$ que também recomendava fortemente seu uso. Entretanto, com o passar do tempo, e novos estudos constantemente vindo à tona, sua proscrição foi necessária, ${ }^{(2)}$ e assim, não há mais a prescrição da alfa drotrecogina ativada para os nossos pacientes de sepse grave e choque séptico.

Dessa forma, um exemplo de reciclagem contínua, e necessidade de outros estudos para o atendimento a esse estado grave, conforme demonstrado em outro estudo que avaliou o impacto do uso de antibióticos, o desfecho clínico, o tempo de permanência hospitalar e os custos hospitalares dos pacientes com sepse grave, demonstraram a necessidade de se conhecer melhor o impacto clínico e 
econômico de ações simples como avaliar a terapêutica adequada para cada paciente e suas devidas necessidades. ${ }^{(46)}$

Outro dado importante resultante da análise dos pacientes ao longo da implementação do protocolo da sepse no Hospital Israelita Albert Einstein, demonstrado através da análise de regressão logística múltipla foi que a adequação antimicrobiana pela hemocultura contribuiu para diminuição da chance de óbito, semelhante ao estudo realizado por lbrahim et al., onde o risco de óbito entre os pacientes que recebiam o antibiótico inadequado era duas vezes maior aos que estavam com a medicação adequada. ${ }^{(7)}$

O uso do antibiótico correto e no tempo certo, é de extrema importância, pois a cada hora de atraso há um acréscimo de 7,6\% nas chances de óbito. ${ }^{(47)}$ Além de contribuir para uma efetiva recuperação do paciente, a adequação antimicrobiana, é também um dos itens importantes de boa prática médica dentro dos critérios de segurança para o paciente. É também um preditor independente de maior sobrevivência para os pacientes com choque séptico, conforme demonstrado por um estudo multicêntrico entre o Canadá e os Estados Unidos, com uma amostra de 2.154 pacientes com choque séptico. ${ }^{(47)}$ Essa prática, portanto, exerce uma grande influência na taxa de mortalidade, pois diminui o tempo de exposição do organismo às toxinas do microrganismo, e à ativação da cascata inflamatória devido à presença do patógeno, e tem sido alvo de estudo de diversos grupos ao redor do mundo. ${ }^{(30,48-50)}$

$O$ uso indiscriminado de antimicrobianos pode contribuir significativamente para o desenvolvimento de resistência bacteriana a esses medicamentos, como demonstrada pela segunda atualização de uma meta-análise quanto à melhoria na prescrição de antibióticos; e consequentemente a uma maior dificuldade em conduzir o caso, além de predispor ao aumento de infecção por Clostridium difficile. ${ }^{(51)}$ Além de expor os pacientes a maiores riscos, pois, determinados antibióticos possuem efeitos colaterais que necessitam cautela, e prescrição racional para uso contínuo e de longo período. ${ }^{(7,8,48)}$

É uma longa discussão o uso empírico dos antibióticos, apesar de ser fortemente indicado pelas diretrizes internacionais e especialistas no assunto. ${ }^{(2,10,33,49)}$ Alguns autores afirmam que é um questionamento sem resposta, não se chegando a um consenso dentre os disponíveis no mercado, qual antibiótico deve ser priorizado. ${ }^{(49)}$ Independente da discussão sobre a priorização do uso do antibiótico, o primordial é não perder tempo para identificar e começar a 
administração do medicamento, principalmente no choque séptico, pois, há evidências para esses pacientes que o tempo foi crucial para sua sobrevida. ${ }^{(52)}$

E concomitante, há a recomendação da realização de culturas não apenas do sangue, mas de diversos fluidos orgânicos para identificar o agente infeccioso. ${ }^{(4)}$ Contudo, ainda não há a recomendação da adequação do antibiótico mediante o resultado positivo da cultura. ${ }^{(53)}$ Isso com certeza contribuirá para uma efetiva recuperação do paciente. $E$ documentar a adequação antimicrobiana no ambiente hospitalar é uma ação passível de métrica, que envolve a segurança do paciente, além de possibilitar comparações entre diferentes instituições (privadas, públicas, nacionais e internacionais), das quais as agências de acreditação de qualidade hospitalar estão sempre em busca dos principais resultados dos indicadores de resultados e desempenho. ${ }^{(44)}$

Demonstrado recentemente por um estudo espanhol, que adequar o antibiótico empírico de um paciente que foi diagnosticado com sepse grave ou choque séptico, ou seja, realizar o de-escalonamento de amplo espectro para o alvoterapêutico de acordo com o resultado da hemocultura com crescimento de algum microrganismo assegurou uma medida segura para a terapêutica, bem como o impacto na mortalidade hospitalar, quanto ao desfecho clínico após 90 dias de sua alta hospitalar. ${ }^{(54)}$ Dessa forma, mesmo se a instituição de saúde, independente do porte de atendimento, não dispor de um especialista no assunto, o resultado da cultura deverá ser a norteadora da conduta antimicrobiana.

A identificação das bactérias, apesar de ser um processo lento e que exige uma coleta de material adequada e de qualidade, portanto, um profissional com tal expertise, está entre as medidas que contribuem, estatisticamente, para a sobrevida do paciente. Nesse estudo foram identificadas bactérias que fazem parte do grupo ESKAPE, ${ }^{(55,56)}$ aos quais possuem extrema importância, devido aos paradigmas de sua patogênese, modo de transmissão e resistência aos antibióticos. ${ }^{(55)}$ Apesar de identificadas essas bactérias, a de maior prevalência na amostra foi a Escherichia coli. A qual pode apresentar em seu mecanismo de ação a produção de beta-lactamase de espectro estendido, que atua diretamente no mecanismo de resistência dos beta-lactâmicos. ${ }^{(56)}$

$\mathrm{Na}$ literatura há relatos sobre a presença de uma bactéria produtora de beta-lactamase de espectro estendido (Escherichia coli ou Klebsiella spp) acarretar em uma predição independente de maior mortalidade, um tempo de 
internação prolongado, retardo no início do antibiótico apropriado, e assim com impacto no custo hospitalar, tanto para a instituição, como para o paciente..$^{(55,56)}$

Dentre a prevalência de agentes microbiológicos identificados nas hemoculturas, a característica principal que os envolve é a de fazer parte da flora bacteriana da pele humana, o que, portanto, medidas como atenção para a constante higiene das mãos entre os profissionais de saúde, por exemplo, influenciaria na redução de possíveis infecções entre os pacientes internados. Não necessariamente realizar com água e sabão, mas com o uso do gel alcoólico pode ser de grande impacto nas taxas de infecções da corrente sanguínea da instituição. ${ }^{(57)}$

Outra característica identificada pelos resultados da hemocultura foi a infecção por apenas um microrganismo, ou seja, a infecção monomicrobiana, em 93\% ( $n=333)$. Esse dado em relação ao estudo SCOPE (Surveillance and Control of Pathogens of Epidemiological Importance) foi superior aos achados estudados por sete anos por esse grupo (março 1995 a setembro de 2002), com 87\%. Além disso, diferente do estudo SCOPE (65\% de bactérias Gram-positivas), ${ }^{(58)}$ dentre os microrganismos mais comuns de crescimento na hemocultura, as bactérias Gramnegativas foram as mais prevalentes, com 57,3\% $(n=219)$ dos casos. É possível que essa prevalência possa ter influenciado no tempo de permanência dos pacientes, bem como casos de complicações e assim mais graves, conforme estudo realizado em hospital-escola dos Estados Unidos, com 1.200 leitos, ${ }^{(46)}$ o que cria possibilidades para posteriores análises dos dados.

A versão brasileira do SCOPE (Brazilian Surveillance and Control of Pathogens of Epidemiological Importance) foi realizada em 2011 por pesquisadores da Universidade Federal de São Paulo, o qual incluíram 16 hospitais de diferentes portes de atendimento e geograficamente distintos no Brasil, com seu principal resultado semelhante ao presente estudo, com bactérias Gram-negativas na sua maioria $(58,5 \%) .{ }^{(59)}$

Resultados semelhantes foram apresentados por um grupo de estudo de Sevilha, na Espanha, aonde a prevalência de microrganismos identificados nas culturas foi de bactérias Gram-negativas, seguido de bactérias Gram-positivas e fungos. ${ }^{(52)}$ Tanto na versão brasileira do SCOPE, como no grupo espanhol, a característica predominante do perfil microbiológico foi semelhante, e isso pode estar fortemente relacionado a fatores climáticos. Sevilha apresenta verão rigoroso, quente e seco. Já no período de inverno as temperaturas não são tão baixas a ponto de 
nevar nessa região. E o Brasil, apesar da sua grande extensão territorial, em sua maior parte do tempo, apresenta clima quente.

Um levantamento que contribui para tal hipótese foi realizado durante ações humanitárias pós-terremoto na região de Porto Príncipe no Haiti, aonde $80 \%$ dos isolados de feridas das vítimas foram de bactérias Gram-negativas. ${ }^{(60)}$ Outro dado que corrobora tal hipótese está no resultado de um estudo entre 23 centros internacionais, o qual demonstrou a variabilidade determinante dos achados para as bactérias Gram-negativas conforme a posição geográfica e as condições sócioeconômicas. ${ }^{(61)}$

Quanto à adequação antimicrobiana nos casos de hemocultura positiva, os dados demonstram boa indicação terapêutica, traduzindo boa prática na condução dos casos graves, de acordo com as taxas dos indicadores acompanhados mensalmente pelos comitês internos do Hospital Israelita Albert Einstein. Porém, apenas em relação a grupo dos fungos, que houve maior falha na indicação terapêutica, sendo dos cinco casos identificados, $60,0 \% \quad(n=3 / 5)$ foram a óbito e nenhum desses pacientes estava com terapêutica adequada. Entretanto, é um cenário passível de mudanças, pois o desenvolvimento de drogas mais efetivas, com melhor biodisponibilidade e segurança estão em rápido progresso. ${ }^{(62)}$

Como limitantes do nosso estudo pontua-se ter sido desenvolvido em único centro, de forma a não permitir comparações entre outros serviços, principalmente em serviços públicos, e também a coleta de dados ter sido realizada apenas em prontuários, portanto, uma coleta retrospectiva. E, como forma de diminuir o viés de interpretação dos dados, não foram incluídos dados microbiológicos de outros potenciais sítios infecciosos, se não apenas os dados microbiológicos das hemoculturas para a avaliação da adequação antimicrobiana.

A característica primária da hemocultura pressupõe um local estéril, portanto, a positividade do exame é um dado fidedigno de infecção, que necessita de intervenção urgente. Já outros locais como, por exemplo, o trato respiratório, urinário, são sabidamente não-estéreis, o que dificulta a interpretação e o tratamento adequado, visto que, é fato a colonização da flora permanente.

Outras informações e ações que ocorreram na instituição para melhoria contínua com o foco na qualidade do atendimento e garantindo a segurança do paciente, concomitante à própria fase de maturidade do protocolo de sepse, podem ter influenciado no resultado do estudo. Desde 2007, o Hospital Israelita Albert Einstein 
tem se empenhado para prevenção da infecção associada à prestação de cuidado à saúde, com a prática da "tolerância zero contra as infecções intra-hospitalares".

Com isso, foi possível observar a redução significativa dos casos de pneumonia associada à ventilação mecânica ${ }^{(63)}$ e mesmo as infecções da corrente sanguínea associada ao uso de cateteres venosos centrais. ${ }^{(64)}$ Além disso, também foram implementados outros programas de melhores práticas na unidade de terapia intensiva, que incluíram o controle glicêmico dos pacientes, devido ao aumento significativo na incidência de hipoglicemia, e mesmo picos de hiperglicemia em pacientes não diabéticos, que além de deixar o organismo do paciente mais vulnerável para o desenvolvimento de infecções, é uma situação que pode comprometer sua recuperação e, assim, aumentar o tempo de permanência hospitalar. ${ }^{(65)}$

Foi adotado o controle de glicose intermediário, pois o controle glicêmico rigoroso dificulta sua efetiva monitorização, já que no ambiente de terapia intensiva os pacientes podem necessitar a qualquer momento de intervenções que possam interferir na rotina de monitorização.

No entanto, é interessante notar que as melhores práticas para o atendimento de pacientes com sepse grave e choque séptico foram melhorando ao longo do tempo na unidade de terapia intensiva de adultos do Hospital Israelita Albert Einstein. O que confirma a nossa crença de que o pacote sepse deve ser considerado como a intervenção que interferiu na taxa de mortalidade de sepse grave e choque séptico, devido a todo o contexto que modificou o atendimento, levou a treinamentos intensivos para impulsionar o reconhecimento imediato desses pacientes, tanto fora do hospital (provenientes do pronto-atendimento), quanto em qualquer unidade de internação do hospital. Proporcionou um atendimento global e sistemático que tem seguramente demonstrado benefícios aos pacientes. 


\section{CONCLUSÕES}

1. Os patógenos mais frequentes identificados nas hemoculturas de pacientes com sepse grave ou choque séptico, caracterizando, portanto o perfil microbiológico dessa amostra foram Escherichia coli, Streptococcus pneumoniae, Staphylococcus epidermidis e Staphylococcus aureus (com poucos casos de patógenos nosocomiais resistentes à meticilina/oxacilina); e Klebsiella pneumoniae.

2. A taxa de adequação antimicrobiana esteve em $72,6 \%$ dos casos com identificação do agente, o que contribuiu para a diminuição da mortalidade nesses pacientes, e a adequação antimicrobiana deve ser um item a ser incorporado como um dos componentes pertencentes da Campanha Sobrevivendo à Sepse.

3. Com o passar dos anos, à medida que a adesão ao protocolo aumentava, a taxa de mortalidade hospitalar foi diminuindo, o que, portanto, reforça a necessidade de continuidade da nossa diretriz institucional de prevenção e tratamento de pacientes com sepse. 
7 ANEXOS

Anexo 1. Aprovação do Comitê de Ética em Pesquisa

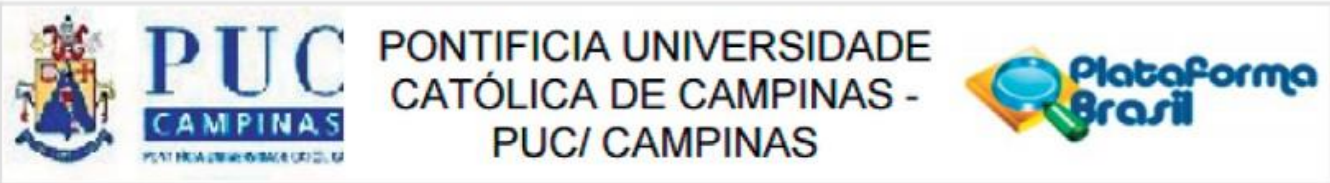

Continuaçăo do Parecer: 265.619

também, solicitado dispensa do TCLE pois a pesquisa será realizada apenas consultando banco de dados de 800 individuos, no período considerado.

Recomendações:

Sem comentáros.

Conclusões ou Pendências e Lista de Inadequações:

Sem comentários.

Situação do Parecer:

Aprovado

Necessita Apreciaçăo da CONEP:

Não

Considerações Finais a critério do CEP:

CAMPINAS, 07 de Maio de 2013

Assinador por:

CARLOS ALBERTO ZANOTTI

(Coordenador)

Endereço: Rodovia Dom Pedro I, Km 136

Bairro: Parque das Universidades

CEP: $13.086-900$

UF: SP Municipio: CAMPINAS

Telefone: (19)3343-6777 Fax: (19)3343-6777

E-mail: comitedeetica@puc-campinas.edu.br 


\section{PUC PONTIFICIA UNIVERSIDADE \\ CATÓLICA DE CAMPINAS - PUC/ CAMPINAS}

\section{PARECER CONSUBSTANCIADO DO CEP}

\section{DADOS DO PROJETO DE PESQUISA}

Título da Pesquisa: Avaliação microbiológica e importăncia da adequaçăo antimicrobiana para os pacientes com sepse grave e choque séptico

Pesquisador: Paula Kiyomi Onaga Yokota

Área Temática:

Versăo: 1

CAAE: 14092913.8 .0000 .5481

Instituiçăo Proponente: Hospital Israelita Albert Einstein-SP

Patrocinador Principal: Financiamento Próprio

\section{DADOS DO PARECER}

Número do Parecer: 265.619

Data da Relatoria: 08/05/2013

\section{Apresentaçăo do Projeto:}

Avaliação microbiológica e importância da adequação antimicrobiana para os pacientes com sepse grave $e$ choque séptico

\section{Objetivo da Pesquisa:}

Determinar o perfil microbiológico bem como a adequaçăo antimicrobiana dos pacientes com sepse grave e choque séptico internados no Hospital Israelita Albert Einstein, internados durante o período de 2005 a 2012.

\section{Avaliaçăo dos Riscos e Beneficios:}

Os pesquisadores consideram como risco "a falta de identificação dos dados a serem buscados restrospectivamente nos prontuários dos pacientes atendidos". Como beneficios destacam " o conhecimento do perfil microbiológico dos pacientes que desenvolveram sepse grave e / ou choque séptico internados no HIAE durante o período de 2005 a 2012, e o quão adequado foi o uso das medicações antimicrobiana para cada paciente".

\section{Comentários e Consideraçōes sobre a Pesquisa:}

Sem comentários.

Consideraçŏes sobre os Termos de apresentação obrigatória:

Os termos foram apresentados e devidamente assinados pelos pesquisadores, tendo sido,

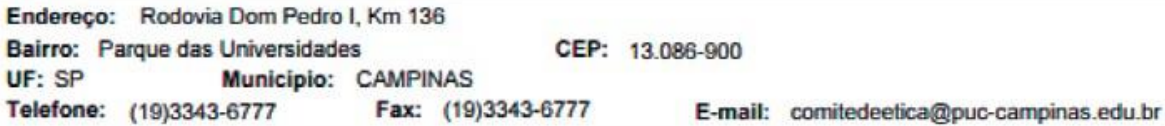

Publicação em periódico:

Yokota PK, Marra AR, Martino MD, Victor ES, Durão MS, Edmond MB, Santos OF. Impact of appropriate antimicrobial therapy for patients with severe sepsis and septic shock - a quality improvement study. PLoS One. 2014;9(11):e104475. 


\section{REFERÊNCIAS}

1. Angus D, van der Poll T. Severe sepsis and septic shock. N Engl J Med. 2013;369:840-51.

2. Dellinger RP, Levy MM, Rhodes A, Annane D, Gerlach H, Opal SM, et al. Surviving Sepsis Campaign: international guidelines for management of severe sepsis and septic shock: 2012 . Crit Care Med. 2013;41(2):580-637.

3. Brasil. Ministério da Saúde. DATASUS. Taxa de mortalidade hospitalar por local de internação - Brasil 2008 a Agosto 2013 [Internet]. 2013 [citado 2015 Out 25]. Disponível em: http://tabnet.datasus.gov.br/cgi/tabcgi.exe?sih/cnv/niuf.def

4. Dellinger RP, Carlet JM, Masur H, Gerlach H, Calandra T, Cohen J, et al. Surviving Sepsis Campaign guidelines for management of severe sepsis and septic shock. Intensive Care Med. 2004;30(4):536-55.

5. Alliance Global Sepsis. World Sepsis day [Internet]. Jena: Alliance Global Sepsis; 2013 [cited 2015 Oct 25]. Available from: http://www.world-sepsis-day.org

6. Shiramizo SC, Marra AR, Durão MS, Paes A, Edmond MB, Pavão dos Santos OF. Decreasing mortality in severe sepsis and septic shock patients by implementing a sepsis bundle in a hospital setting. PLoS One. 2011;6(11):e26790.

7. Ibrahim EH, Sherman G, Ward S, Fraser VJ, Kollef MH. The influence of inadequate antimicrobial treatment of bloodstream infections on patient outcomes in the ICU setting. Chest. 2000;118(1):146-55.

8. Zaragoza R, Artero A, Camarena JJ, Sancho S, González R, Nogueira JM. The influence of inadequate empirical antimicrobial treatment on patients with bloodstream infections in an intensive care unit. Clin Microbiol Infect. 2003;9(5):412-8.

9. Kang Cl, Kim SH, Park SW, Choe YJ, Oh MD, Choe KW. Pseudomonas aeruginosas bacteremia:risk factors for mortality and influence of delayed receipt of effective antimicrobial therapy on clinical outcome. Clin Infect Dis. 2003;37(6):745-51.

10. Instituto Latino-Americano para Estudos da Sepse. Sepse: um problema de saúde pública/Instituto Latino-Americano para Estudos da Sepse. Brasília: Conselho Federal de Medicina; 2015

11. Vincent JL, Abraham E. The last 100 years of sepsis. Am J Respir Crit Care Med. 2006;173(3):256-63.

12. Angus DC, Wax RS. Epidemiology of sepsis: an update. Crit Care Med. 2001;29(7 Suppl):S109-S116.

13. Angus DC, Linde-Zwirble WT, Lidicker J, Clermont G, Carcillo J, Pinsky MR. Epidemiology of severe sepsis in the United States: analysis of incidence, outcome, and associated costs of care. Crit Care Med. 2001;29(7):1303-10.

14. Cohen J, Vincent JL, Adhikari NKJ, Machado FR, Angus DC, Calandra T, et al. Sepsis: a roadmap for future research. Lancet Infect Dis. 2015;15(5): 581-614. 
15. Decker B, Mansur H. Bad bugs, no drugs: are we part of the problem, or leaders in developing solutions? Crit Care Med. 2015;43(6):1153-5.

16. Vaidotas M, Yokota PKO, Marra AR, Camargo TZ, Victor E da S, Gysi DM,et al. Measuring hand hygiene compliance rates at hospital entrances. Am J Infect Control. 2015;43(7):694-6.

17. Marra AR, Edmond MB. New technologies to monitor healthcare worker hand hygiene. Clin Microbiol Infect. 2014;20(1):29-33.

18. Poeze M, Ramsay G, Gerlach H, Rubulotta F, Levy M. An international sepsis survey: a study of doctors' knowledge and perception about sepsis. Crit Care. 2004;8(6):R409-13.

19. Assunção M, Akamine N, Cardoso GS, Mello PV, Teles JM, Nunes AL, et al. Survey on physicians' knowledge of sepsis: do they recognize it promptly? J Crit Care. 2010;25(4):545-52.

20. Bone RC, Balk RA, Cerra FB, Dellinger RP, Fein AM, Knaus WA, et al. Definitions for sepsis and organ failure and guidelines for the use of innovative therapies in sepsis. The ACCP/SCCM Consensus Conference Committee. American College of Chest Physicians/Society of Critical Care Medicine. Chest. 1992;101(6):1644-55.

21. Levy MM, Fink MP, Marsahll JC, Abraham E, Angus DC, Cook D, et al. 2001 SCCM/ESICM/ACCP/ATS/SIS International sepsis definitions conference. Crit Care Med. 2003;31(4):1250-6.

22. Nguyen HM, Smith D. Sepsis in the 21st century: recent definitions and therapeutic advances. Am J Emerg Med. 2007;25(5):564-71.

23. Kaukonen KM, Bailey M, Pilcher D, Cooper DJ, Bellomo R. Systemic inflammatory response syndrome criteria in defining severe sepsis. N Engl J Med. 2015;372(17):1629-38.

24. Osborne TM, Phillips G, Lemeshow S, Townsend S, Schorr CA, Levy MM, Dellinger RP. Sepsis severity score: an internationally derived scoring system from the surviving sepsis campaign database. Crit Care Med. 2014; 42(9):1969-76.

25. Levy MM, Rohodes A, Phillips GS, Townsend SR, Schorr CA, Beale R. Surviving sepsis campaign: association between performance metrics and outcomes in a 7.5-year study. Crit Care Med. 2015;43(1):3-12.

26. Rivers E, Nguyen B, Havstad S, Ressler J, Muzzin A, Knoblich B, et al. Early goaldirected therapy in the treatment of severe sepsis and septic shock. $\mathrm{N}$ Engl J Med. 2001;345(19):1368-77.

27. Miller RR, Dong L, Nelson NC, Brown SM, Kuttler KG, Probst DR, et al. Multicenter implementation of severe sepsis and septic shock treatment bundle. Am J Respir Crit Care Med. 2013;188(1):77-82.

28. ProCESS investigators, Yealy DM, Kellum JA, Huang DT, Barnato AE, Weissfeld LA, et al. A randomized trial of protocol-based care for early septic shock. N Engl J Med. 2014;370(18):1683-93.

29. Pike F, Yealy DM, Kellum JA, Huang DT, Barnato AE, Eaton TL, et al. Protocolized 
care for early septic shock (ProCESS) statistical analysis plan. Crit Care Resusc. 2013;15(4):301-10.

30. Cardoso T, Ribeiro O, Aragão I, Costa-Pereira A, Sarmento A. The impact of healthcareassociated infection on mortality: failure in clinical recognition is related with inadequate antibiotic therapy. PLoS One. 2013;8(3):e58418.

31. Hall MJ, Williams SN, DeFrances CJ, Golosinskiy A. Inpatient care for septicemia or sepsis: a challenge for patients and hospitals. NCHS Data Brief. 2011(62):1-8.

32. Mayr FB, Yende S, Angus DC. Epidemiology of severe sepsis. Virulence. 2014;5(1):4-11.

33. Ferrer R, Martin-Loeches I, Phillips G, Osborn TM, Townsend S Dellinger RP, et al. Empirirc antibiotic treatment reduces mortality in severe sepsis and septic shock from the first hour: results from a guideline-based performance improvement program. Crit Care Med. 2014;42(8):1749-55.

34. Cohen J, Cristofaro P, Carlet J, Opal S. New method of classifying infections in critically ill patients. Crit Care Med. 2004;32(7):1510-26.

35. Marra AR, Wey S, Castelo A, Gales AC, Cal RG, do Cardmo Fo JR, et al. Nosocomial bloodstream infections caused by Klebsiella pneumonia impact of extended-spectrum betalactamase $(E S B L)$ production on clinical outcome in a hospital with high ESBL prevalence. BMC Infect Dis. 2006;6(1):24.

36. Marra AR, Pereira CA, Gales AC, Menezes LC, Cal RG, de Souza JM, et al. Bloodstream infections with metallo-beta-lactamase-producting Pseudomonas aeruginosa: epidemiology, microbiology, and clinical outcomes. Antimicrob Agents Chemother. 2006;50(1):388-90.

37. Hiramatsu K, Hanaki H, Ino T, Yabuta K, Oguri T, Tenover F. Methicillin- resistant Staphylococcus auresus clinical strain with reduced vancomycin suscpe. J Antimicrob Chemother. 1997;40(1):135-6.

38. Bartley J. First case of VRSA identified in Michigan. Infect Control Hosp Epidemiol. 2002;23(8):480.

39. Gonçales PDS, Polessi JA, Bass LM, Santos GPD, Yokota PKO, Laselva CR, et al. Reduced frequency of cardiopulmonary arrests by rapid response teams. Einstein (São Paulo). 2012;10(4):442-8.

40. Clinical and Laboratory Standards Institute. Performance Standards for antimicrobial susceptibility testing: sixteenth informational supplement. Wayne, PA; 2006.

41. Makdisse M, Katz M, Corrêa A, Forlenza LMA, Perin MA, Brito Jr FS, et al. Efeito da implementação de um protocolo assistencial de infarto agudo do miocárdio sobre os indicadores de qualidade. Einstein (São Paulo). 2013;11(3):357-63.

42. Knaus WA, Draper EA, Wagner DP, Zimmerman JE. APACHE II: a severity of disease classification system. Crit Care Med. 1985;13(10):818-29.

43. Nygård ST, Langeland N, Flaatten HK, Fanebust R, Haugen O, Skrede S. Aetiology, antimicrobial therapy and outcome of patients with community acquired severe sepsis: a prospective study in a Norwegian university hospital. BMC Infect Dis. 2014;14:121. 
44. Glasziou P, Ogrinc G, Goodman S. Can evidence-based medicine and clinical quality improvement learn from each other? BMJ Qual Saf. 2011;20(Suppl 1):i13-17.

45. Martin G, Brunkhorst FM, Janes JM, Reinhart K, Sundin DP, Garnett K, Beale R. The international PROGRESS registry of patients with severe sepsis: drotrecogin alfa (activated) use and patient outcomes. Crit Care. 2009;13(3):R103.

46. Micek S, Johnson MT, Reichley R, Kollef MH. An institutional perspective on the impact of recent antibiotic exposure on length of stay and hospital costs for patients with gram-negative sepsis. BMC Infect Dis. 2012;12:56.

47. Kumar A, Roberts D, Wood K, Light B, Parrillo JE, Sharma S, et al. Duration of hypotension before initiation of effective antimicrobial therapy is the critical determinant of survival in human septic shock. Crit Care Med. 2006; 34(6):1589-96.

48. Zubert S, Funk DJ, Kumar A. Antibiotics in sepsis and septic shock: like everything else in life, timing is everything. Crit Care Med. 2010;38(4):1211-2.

49. Gaieski DF, Mikkelsen ME, Band RA, Pines JM, Massone R, Furia FF, et al. Impact of time to antibiotics on survival in patients with severe sepsis or septic shock in whom early goal-directed therapy was initiated in the emergency department. Crit Care Med. 2010;38(4):1045-53.

50. Proudfoot AG, McAuley DF, Hind M, Griffiths MJ. Translational research: what does it mean, what has it delivered and what might it deliver? Curr Opin Crit Care. 2011;17(5):495503.

51. Davey P, Brown E, Fenelon L, Finch R, Gould I, Hartman G, et al. Interventions to improve antibiotic prescribing practices for hospital inpatients. Cochrane Database Syst Rev. 2005;19(4):CD003543.

52. Garnacho-Montero J, Gutiérrez-PizarrayaA, Escoresca-OrtegaA, Fernández- Delgado E, López-Sánchez JM. Adequate antibiotic therapy prior to ICU admission in patients with severe sepsis and septic shock reduces hospital mortality. Crit Care. 2015;19:302.

53. Barochia AV, Cui X, Eichacker PQ. The surviving sepsis campaign's revised sepsis bundles. Curr Infect Dis Rep. 2013;15(5):385-93.

54. Garnacho-Montero J, Gutiérrez-Pizarraya A, Escoresca-Ortega A, Corcia- Palomo Y, Fernández-Delgado E, Herrera-Melero I, et al. De-escalation of empirical therapy is associated with lower mortality in patients with severe sepsis and septic shock. Intensive Care Med. 2014;40(1):32-40.

55. Rice LB. Federal funding for the study of antimicrobial resistance in nosocomial pathogens: no ESKAPE. J Infect Dis. 2008;197(8):1079-81.

56. Boucher HW, Talbot GH, Bradley JS, Edwards JE, Gilbert D, Rice LB, et al. Bad bugs, no drugs: no ESKAPE! An update from the Infectious Diseases Society of America. Clin Infect Dis. 2009;48(1):1-12.

57. Marra AR, Pavão dos Santos OF, Cendoroglo Neto M, Edmond MB. Positive Deviance: a new tool for infection prevention and patient safety. Curr Infect Dis Rep. 2013;15(6):544-8. 
58. Wisplinghoff H, Bischoff T, Tallent S, Seifert H, Wenzel RP, Edmond MB. Nosocomial bloodstream infections in US hospitals: analysis of 24,179 cases from a prospective nationwide surveillance study. Clin Infect Dis. 2004;39(3):309-37.

59. Marra AR, Camargo LF, Pignatari AC, Sukiennik T, Behar PR, Medeiros EA, et al. Nosocomial bloodstream infections in Brazilian Hospitals: analysis of 2,563 cases from a prospective nationwide surveillance study. J Clin Microbiol. 2011;49(5):1866-71.

60. Marra AR, Valle Martino MD, Ribas MR, Rodriguez-Taveras C, Pavão dos Santos O. Microbiological findings from the Haiti disaster. Travel Med Infect Dis. 2012;10(3):157-61.

61. Fisman D, Patrozou E, Carmeli Y, Perencevich E, Tuite AR, Mermel LA, et al. Geographical variability in the likelihood of bloodstream infections due to Gram-negative bacteria: correlation with proximity to the Equator and health care expenditure. PloS One. 2014;9(12):e114548.

62. Dimopoulos G, Antonopoulou A, Armaganidis A, Vincent JL. How to select an antifungal agent in critically ill patients. J Crit Care. 2013;28(5):717-27.

63. Marra AR, Cal RG, Silva CV, Caserta RA, Paes AT, Moura Jr DF, et al. Successful prevention of ventilator-associated pneumonia in an intensive care setting. Am J Infect Control. 2009;37(8):619-25.

64. Marra AR, Cal RG, Durão MS, Correa L, Guastelli LR, Moura Jr DF, et al. Impact of a program to prevent central line-associated bloodstream infection in the zero tolerance era. Am J Infect Control. 2010;38(6):434-9.

65. Durao MS, Marra AR, Moura DF, Almeida SM, Fernandes CJ, Akamine N, et al. Tight glucose control versus intermediate glucose control: a quasi- experimental study. Anaesth Intensive Care. 2010;38(3):467-73. 


\begin{abstract}
Purpose: To determine the microbiological profile and the appropriateness of antimicrobial therapy in patients with severe sepsis and septic shock hospitalized at adult intensive care unit of a private hospital in São Paulo. Methods: This study was conducted in the ICU of a tertiary care, private hospital in São Paulo, Brazil. A retrospective cohort study was conducted from July 2005 to December 2012 in patients with severe sepsis and septic shock. Results: A total of 1,279 patients were identified with severe sepsis and septic shock, of which 358 (32.1\%) had bloodstream infection (BSI). The inpatient mortality rate was $29 \%$. In evaluation of the sepsis bundle, over time there was a progressive increase in serum arterial lactate collection, obtaining blood cultures prior antibiotic administration, administration of broad-spectrum antibiotic within 1 hour, and administration of appropriate antimicrobials, with statistically significant differences, after adjustment for other covariates the administration of appropriate antimicrobial therapy was associated with a decrease in mortality in patient with severe sepsis and septic shock $(p=0.023)$. Conclusions: The administration of appropriate antimicrobial therapy was independently associated with a decline in mortality in patients with severe sepsis and septic shock due to bloodstream infection. As protocol adherence increased over time, the crude mortality rate decreased, which reinforces the need to implement institutional guidelines and monitor appropriate antimicrobial therapy compliance.
\end{abstract}

